\title{
LA DEPURACIÓN DEL MAGISTERIO PRIMARIO EN LA CIUDAD DE SEGOVIA (1936-1939)
}

\author{
The Purge of the School Teachers in the City of Segovia (1936-1939)
}

\author{
Miriam Sonlleva Velasco \\ miriam.sonlleva@uva.es \\ Universidad de Valladolid. España \\ Carlos Sanz Simón ${ }^{1}$ \\ csa02@ucm.es \\ Universidad Complutense de Madrid. España \\ Fecha de recepción: 05/04/2020 \\ Fecha de aceptación: 04/05/2020
}

RESUMEN: La depuración del magisterio durante la Guerra Civil ha sido objeto de interés para muchos historiadores, que han tratado de cuantificar este proceso depurador atendiendo a variables regionales y han dejado al margen los perfiles individuales de aquellos docentes que vivieron la purga. Profundizar en sus biografías es hoy una tarea necesaria para avanzar en esta línea de investigación. El objetivo de este artículo es conocer cómo se llevó a cabo el proceso depurador del magisterio en la ciudad de Segovia (1936-1939) atendiendo a variables biográficas y de género. A través del análisis de los cargos que les fueron imputados a los treinta y siete maestros y las maestras que trabajaban en las escuelas públicas de la capital y las sanciones que recibieron, llegaremos a conocer el perfil del magisterio segoviano en el franquismo. Partimos de una metodología histórico-educativa que se sustenta en tres fuentes fundamentales: los expedientes de depuración de los docentes, sus expedientes profesionales e información biográfica de cada uno de ellos recogida en diversos archivos segovianos. Los resultados revelan cómo un grupo de maestros y maestras con un espíritu renovador, que fueron reconocidos por la administración educativa por su labor al frente de las escuelas y por sus inquietudes pedagógicas antes de la guerra, sufrieron la separación del cargo y en algunos casos la muerte. Su destino fue distinto al de aquellos docentes que cumplieron con un modelo educativo tradicional y que fueron premiados tras la depuración por su incondicional apoyo a la patria y el catolicismo.

${ }^{1}$ Esta investigación se ha llevado a cabo gracias a la concesión de un contrato predoctoral de personal investigador en formación de la Universidad Complutense de Madrid cofinanciado por el Banco Santander (CT17/17-CT18/17). 
Palabras clave: depuración; franquismo; género; magisterio; Segovia.

ABSTRACT: The purge of the primary school teachers during the Spanish civil war has been an object of interest for many historians, who have tried to quantify this purifying process based on regional variables and have left out the individual profiles of those teachers who experienced the purge. Digging deeper into their biographies is today a necessary task to advance this line of research. The objective of this article is to know how the purification process of the teaching profession was carried out in the city of Segovia (1936-1939) taking into account biographical and gender variables. Through the analysis of the charges that were imputed to the thirty-seven teachers and the teachers who worked in the public schools of the capital and the sanctions that they received. We will get to know the profile of the Segovian magisterium in the Franco regime. We start from a historicaleducational methodology that is based on three fundamental sources: the records of the purification of teachers, their professional records and biographical information on each one of them collected in various Segovian files. The results reveal how a group of teachers with a renovating spirit, who were recognized by the educational administration for their work at the head of the schools and for their pedagogical concerns before the war, suffered the separation from office and in some cases the death. Their fate was different from that of those teachers who fulfilled a traditional educational model and who were awarded after the purge for their unconditional support for the homeland and Catholicism.

Keywords: purge; Francoism; gender; primary school teachers; Segovia.

SUMARIO: 1. Introducción. 2. La depuración del magisterio en Segovia. 3. Metodología. 4. Análisis de datos. 4.1. Los cargos vertidos sobre el magisterio público de la capital segoviana. 4.2. Las sanciones a las que se vieron sometidos los maestros y maestras. 4.3. Maestros afines: los docentes de la Nueva España. 5. Discusión y conclusiones. 6. Referencias bibliográficas.

\section{INTRODUCCIÓN}

La depuración del magisterio primario durante el periodo de la guerra civil y la inmediata posguerra ha sido objeto de un ingente número de publicaciones desde finales del siglo $x x^{2}$. Estas publicaciones han sido clave para establecer un consenso sobre la idea de que el Magisterio fue el cuerpo de la administración que sufrió la mayor persecución por parte del régimen franquista. Y lo fue porque los publicistas de la sublevación se encargaron de repetir hasta la extenuación que los maestros habían sido los principales responsables de la degradación espiritual que había conducido a España a la contienda (Morente, 2001).

La represión constituyó el elemento fundamental para alejar y eliminar a aquellos maestros que facilitaron el acceso a la educación de todos los sectores sociales y apostaron por un modelo educativo coeducativo, laico y democrático. En sus

2 Hernández y Sánchez (2008) elaboraron un completo estudio sobre el elenco de publicaciones realizadas en España sobre esta temática que da muestras de la importancia que los investigadores han dado a la depuración docente y también de los vacíos temáticos que sigue presentando este foco de investigación. 
puestos quedaron quienes luchaban por una educación tradicional, segregadora y arcaica.

Pero para la consolidación del franquismo no solo se necesitaba un modelo de maestro adepto al Régimen y capaz de reproducir la nueva ideología, sino un grupo de profesionales capaces de controlar la memoria y la historia de España (Martín y Grana, 2019). En el olvido social del pasado y la manipulación del conocimiento se encontraba el sustento para mantener en el tiempo a la dictadura.

La explicación de la mecánica del proceso depurador, sus fundamentos legales y su aplicación práctica es por todos conocida. En estos últimos años se ha hecho además un esfuerzo considerable por desvelar datos de esta depuración en muchas regiones españolas. Sin ánimo de establecer un estado de la cuestión preciso sobre la temática, sirvan como ejemplo los trabajos realizados en algunas provincias de Castilla y León (Pablo, 2004; Dueñas y Grimau, 2004; Vega, 2004 y 2010; García, 2005, Martínez Pereda, 2006, 2008; Berzal y Rodríguez, 2010; Mayo, 2012; Ruiz, 2017); Castilla- La Mancha (Ortiz, 1991; Pont, 2001, 2006; Ramos 2004, 2005 y 2006; Benito, 2008; Gallego, 2017); Galicia (Costa, 1997; Cid, 2017; Costa y Bolaño, 2017; Gabriel, 2017; García, 2017; Porto y Vázquez, 2017); Asturias (Uría, 1984); Cataluña (Morente, 1994 y 1996; González y Marqués, 1996; Plaza, 2015); Andalucía (Pozo, 2001, 2010; Pozo y Ventajas, 2003; Rojas, 2011; San Millán, 2016; Tristán, 2017); Cantabria (Gudín, Gutiérrez, Obregón y Menéndez, 2012); Comunidad Valenciana (Fernández y Agullo, 1999a, 1999b; Vilanova, 2015; Doménech, 2016; Vilanova y Monlleó, 2019); Extremadura (Chaves, 1995; Rodríguez, 2012); Aragón (Abós, 2015); Canarias (Negrín, 2010); Comunidad de Madrid (Martínez Martínez, 2015); Navarra (Martínez Aznal, 2015); Murcia (Jiménez, 1997); y Baleares (Miró, 1998).

Estos estudios han sido fundamentales para realizar aproximaciones a los resultados finales de la depuración docente (Martín y Grana, 2019) o para establecer comparaciones entre regiones (Ramos, 2006). Sin embargo, la obsesión de los investigadores por cuantificar la depuración del Magisterio ha dejado en muchos casos al margen los matices y perfiles individuales de este complejo asunto depurador. El historiador José María Hernández Díaz señalaba en una de las reseñas realizadas a propósito del libro Muerte y represión en el magisterio de Castilla y León, una de las obras más completas que conocemos sobre la represión docente en la región española que es objeto de nuestra investigación, que se hacía pertinente alejarnos de los datos cuantitativos y profundizar en los cualitativos de esta depuración (Hernández, 2012).

Poner nombre y apellidos a cada expediente de depuración, profundizar en las biografías de los maestros, analizar las peculiaridades del proceso depurador desde una perspectiva de género, o descubrir la participación de los docentes en sindicatos y agrupaciones políticas de acuerdo con el contexto de enseñanza son hoy aspectos en muchas regiones desconocidos y necesarios para profundizar en este campo de investigación que, como se ha podido comprobar previamente, aún en nuestros días resulta de gran interés para los historiadores de la educación. 
Estos aspectos son los que nos han empujado a iniciar la presente investigación, que tiene como principal objetivo ahondar en la depuración del magisterio de primera enseñanza ${ }^{3}$ de la ciudad de Segovia (1936-1939) desde una panorámica cualitativa y de género. En este sentido, partimos de la necesidad de profundizar en este proceso de forma diferenciada en función el sexo del profesorado. Ahondando en esta idea, Pérez (2008) señala cómo las maestras fueron víctimas de una serie de cargos, sobre todo de carácter moral y religioso, así como aspectos que podríamos calificar de superficiales o testimoniales, tales como su conducta en el plano personal o de gestos en el espacio público.

En el marco de la presente investigación, nos marcamos como objetivos específicos: a) conocer los cargos a los que fueron sometidos los maestros y las maestras de la capital segoviana; b) profundizar en las sanciones que recibieron los docentes; c) analizar el perfil del grupo de profesionales del magisterio que no recibieron ningún tipo de sanción tras la depuración y que se convirtieron en los referentes del magisterio segoviano durante la dictadura.

Se pretende, en definitiva, avanzar en la labor realizada en la provincia de Segovia sobre la temática de la depuración del magisterio en los comienzos de la dictadura (Dueñas y Grimau, 2004; Vega, 2002, 2004, 2010) atendiendo a las peticiones de las nuevas corrientes historiográficas que se alejan de los números para penetrar en las biografías de quienes sufrieron el proceso depurador.

\section{LA DEPURACIÓN DEL MAGISTERIO EN SEGOVIA}

Segovia, junto con las provincias que conforman hoy la región de Castilla y León fue uno de los territorios que quedaron en manos de los rebeldes pocos días después del comienzo de la sublevación. El triunfo del golpe militar tuvo unas consecuencias directas en la imposición de la ideología dominante en la provincia. Las autoridades no dudaron en hacer uso de la violencia, la coerción y el miedo como herramientas clave no solo para el exterminio del enemigo y el control de la población, sino para demostrar públicamente su poder.

Como en todas las zonas controladas por los sublevados, pronto se llevó a cabo la depuración de los funcionarios locales y provinciales. Pero de entre todos aquellos funcionarios sospechosos de tener ideas contrarias al nacionalcatolicismo hubo un cuerpo en el que el franquismo fijó la más estricta urgencia de este proceso depurador: el Magisterio. La atención que el régimen de Franco puso desde el comienzo de la sublevación en la depuración de este personal a

${ }^{3}$ En este trabajo hemos tenido en cuenta a aquellos docentes que impartían sus enseñanzas en el periodo de enseñanza elemental, en el de perfeccionamiento y en el de iniciación profesional, según la Ley Primaria de 1945. 
su cargo se hace constar en las disposiciones decretadas desde el comienzo de la guerra.

El hecho de que durante varias décadas el Magisterio en todos sus grados y cada vez con más raras excepciones haya estado influido y casi monopolizado por ideologías e instituciones disolventes, en abierta oposición con el genio y tradición nacional, hace preciso que en los solemnes momentos por que atravesamos se lleve a cabo una revisión total y profunda en el personal de Instrucción Pública, trámite previo a una reorganización radical y definitiva de la enseñanza, extirpando así de raíz esas falsas doctrinas que con sus apóstoles han sido los principales factores de la trágica situación a que fue llevada nuestra patria (Decreto 66 de 8 de noviembre de 1936, p. 153).

La depuración del magisterio fue, por tanto, una prioridad política para el franquismo. La nueva élite política era consciente de que, una vez ganada la revolución en la calle, el nuevo orden solo podía sostenerse a través de una acción continuada sobre las voluntades más jóvenes (Hernández Huerta, 2004, p. 11). Era urgente devolver al aula el espíritu católico y tradicional y formar a una masa juvenil sumisa, sin capacidad crítica y paralizada por el miedo. Para ello, se hacía preciso contar con un profesorado afín a estas premisas, que restableciera la educación de un siglo atrás y borrara de la mente colectiva la labor de aquellos que habían perseguido a través de sus acciones formar ciudadanos libres. Así, se expresa en la Circular 7 de diciembre de 1936 que:

El carácter de la depuración que hoy se persigue no es punitivo, sino también preventivo. Es necesario garantizar a los españoles que con las armas en la mano y sin regateos de sacrificios y sangre salvan la causa de la civilización, que no se volverá a tolerar, ni menos a proteger y subvencionar a los envenenadores del alma popular primeros y mayores responsables de todos los crímenes y destrucciones que sobrecogen al mundo y han sembrado de duelo la mayoría de los hogares honrados de España (p. 360).

Las comisiones depuradoras se crearán por el Decreto número 66 de 8 de noviembre de 1936 y tendrán cuatro categorías, en función del colectivo docente sobre el que se ha de actuar: A) y B) para profesorado universitario; C) para personal adscrito a institutos, Escuelas Normales, de Comercio, Artes y Oficios, Inspectores de Primera Enseñanza, etc.; y la comisión D) encargada del personal de magisterio. En el caso de Segovia, al no existir Universidad, solo se crearon la Comisión C) y D). Los integrantes de dichas comisiones eran personas elegidas por el presidente de la Junta Técnica del Estado a propuesta de la Comisión de Cultura y Enseñanza siendo sus cargos irrenunciables (Vega, 2010, p. 327).

En Segovia, la Comisión depuradora D) estaba presidida por el Catedrático Daniel Fraga Aguiar, director del Instituto Nacional de Segunda Enseñanza de Segovia desde 
diciembre de 1936. ${ }^{4}$ Junto a él se encontraban un inspector de Primera Enseñanza, el presidente de la Asociación de Padres de Familia y dos personas de máximo arraigo y solvencia moral técnica. Como secretario fue nombrado Jesús Tablado Santamaría, dirigente de la Federación Católica Agraria, Delegado Provincial de Trabajo y concejal del Ayuntamiento de Segovia (Vega, 2010, pp. 327-328). La misión principal de esta comisión era formular propuestas razonadas de suspensión o separación del personal de magisterio con destino en el territorio de su jurisdicción ${ }^{5}$.

En las Comisiones depuradoras se depositaba el resurgir de una Nueva España. Su misión resultaba clave para garantizar la implantación de una enseñanza acorde con los ideales del nuevo gobierno. Por ello, desde la Circular 7 de diciembre de 1936, se hacía sentir entre las personas encomendadas para tal fin la responsabilidad de cumplir con el espíritu patriótico y alejarse del sentimentalismo. El objetivo no era otro que devolver a España su tradición moral y ver «amanecer en alborada jubilosa un nuevo siglo de oro para gloria de la Cristiandad, de la civilización y de España» (p. 361). Su labor resultaba clave para contagiar a cuantos tuvieran que realizar los informes sobre la conducta de los maestros.

Entre las autoridades que estaban obligadas a informar de la conducta de los maestros en la capital se encontraba el Gobernador civil, Manuel Pérez Mirete. Abogado alicantino nacido en 1884, Pérez Mirete se inició como concejal del Ayuntamiento de Alicante y diputado provincial en 1909. En 1915 fue nombrado jefe del partido conservador en Alicante, cargo que abandonó en 1918 para sumarse al Partido Maurista. En este mismo año fundó junto a otros cargos el diario conservador El Tiempo, siendo después director y gerente de dicha publicación. Durante la dictadura de Primo de Rivera presidió la Asociación de la Prensa de Alicante y la entidad Alicante Atracción. En 1930 fue elegido presidente de la Diputación de Alicante y durante el periodo republicano formó parte de la Derecha regional. Proclamada la guerra civil, Pérez Mirete se posicionó junto a los sublevados, hecho que le sirvió para ser nombrado gobernador de la provincia de Segovia en 1937 (Paniagua, 2003, p. 435). Su labor en la depuración del magisterio de la capital fue clave para informar sobre los antecedentes de los maestros y maestras, a pesar de que, como hemos podido comprobar, el Gobernador no tenía ningún vínculo con la ciudad de Segovia.

Otra de las autoridades que emitía su informe en el proceso depurador desde 1936 era el comandante de la Guardia Civil de Segovia, Evaristo Rubio Velasco, cargo reputado en la capital, pues llevaba 23 años de servicio en Segovia ${ }^{6}$. En su informe recogía la actividad política del maestro informado, así como sus actitudes

${ }^{4}$ Boletín Oficial del Estado, 22 de diciembre de 1936, n. 64

${ }^{5}$ Boletín Oficial del Estado, 11 de septiembre de 1936, n. 27 . Decreto 66 de 8 de noviembre de 1936.

${ }^{6}$ Boletín Oficial del Estado, 30 de junio de 1938, p. 8098. 
y conductas patrióticas y religiosas en la escuela. Tras finalizar el conflicto bélico, ocupa su puesto Manuel Prieto Santiago, agente de la brigada de la comandancia de la Guardia Civil número 301 de Segovia.

Junto a estas autoridades, en todos los expedientes de la capital segoviana aparece el informe del alcalde de Segovia, Andrés Reguera Antón. Su militancia en partidos derechistas durante la Segunda República fue clave para su nombramiento como alcalde de la capital el 10 de octubre de 1936 por las autoridades militares, cargo que sirvió hasta $1947^{7}$. Condecorado con la Cruz Roja del Mérito Militar en $1939^{8}$, Reguera tenía un marcado carácter autoritario. Sus informes sobre los maestros condensaban información no solo de su significación política, sino también de la afiliación a asociaciones y la actuación de los docentes en la escuela.

El informe del cura párroco también era significativo para conocer si el maestro cumplía con su misión educativa cristiana y españolista. En Segovia, estos informes eran firmados por los sacerdotes de las parroquias cercanas a los centros donde los maestros prestaban sus servicios. El cura párroco del barrio del Salvador, Ladislao Siras y el cura ecónomo de San Millán, Fausto Velicia, informaban sobre los docentes de Graduada de niñas n. 2 del barrio de Santa Eulalia, el Grupo Escolar Colmenares y las escuelas del barrio de San Lorenzo. El de San Millán, Pedro Gozalo, informaba sobre los maestros de la Graduada número 1 de niños y la Graduada número 1 de niñas de la Plaza de los Huertos, así como de la Escuela Graduada aneja a la Normal; y Simón Gómez -cura de la feligresía de San Marcos-era el informante de la Escuela de las escuelas de dicho barrio. Tenemos que destacar en este punto, que algunos expedientes de depuración en vez de contar con el informe del párroco de la feligresía donde se encontraba la escuela cuentan con el del sacerdote del pueblo donde había ejercido el maestro su labor, años antes de ocupar su cargo en la ciudad.

Por último, los vecinos de reconocida ideología conservadora y también maestros Desiderio López Velicia y Cipriano Martín Casado, eran los encargados de informar sobre la labor pedagógica de los afectados. De marcado carácter católico y ambos pertenecientes a la Asociación de Maestros Españoles (el primero de ellos era su presidente), fueron las personas elegidas para valorar el comportamiento de sus compañeros al frente de la escuela.

La Comisión Depuradora hacía llegar un cuestionario al maestro y a las autoridades y personas encargadas de la depuración cuyas preguntas se agrupaban en los siguientes apartados: conducta social, en la que se preguntaba por las relaciones con las autoridades, con el vecindario y la intervención en asuntos de obreros; conducta particular, que trataba de conocer la conducta digna del maestro en asuntos

\footnotetext{
${ }^{7}$ Archivo del Congreso de Diputados, Serie documentación electoral, 182 n.o 5 y 189 n.․ 2; Archivo Municipal de Segovia.

${ }^{8}$ Orden 15 de septiembre de 1939. Boletín Oficial del Estado, n. 265, p. 527.
} 
públicos y religiosos; actuación y protagonismo político, la propaganda dentro y fuera de la escuela, la lectura y difusión de prensa de izquierdas y las manifestaciones y actos extremistas; la actuación sindical; y otros datos de interés como sanciones previas, paradero actual y otras observaciones que se estimasen oportunas para conocer el grado de cumplimiento de la labor del maestro (Gutiérrez, 2010, pp. 208-211).

Dada la importancia que el Gobierno de Burgos otorgó a las acciones depuradoras, se intentó recabar en el menor tiempo posible todos los informes pertinentes para que la Comisión pasara posteriormente a su estudio. Si los informes no mostraban elementos de juicio para declarar una posible culpabilidad que derivara en sanción, el expediente finalizaba. En caso contrario, se elaboraba un pliego de cargos que recogía la acusación. El plazo para presentar el pliego de descargos era de diez días. Una vez presentado el pliego de descargos, las Comisiones podían ampliar las diligencias probatorias y recabar nuevos informes. Finalizado este proceso se proponía la sanción pertinente.

Las competencias que tenían las Comisiones depuradoras no eran la aplicación de penas, sino la proposición de estas:

No compete a las Comisiones depuradoras el aplicar las penas que los códigos señalan a los autores por inducción por estar reservada esta facultad a los Tribunales de Justicia, pero sí proponer la separación inexorable de sus funciones magistrales de cuantos directa o indirectamente han contribuido a sostener y propagar a los partidos, ideario e instituciones del llamado Frente Popular. (Circular 7 de diciembre de 1936, p. 360).

Estas propuestas de sanción eran en principio tres, de acuerdo con la Orden de 10 de noviembre de 1936 y la Circular 7 de diciembre de 1936: a) La libre absolución para aquellos que puestos en entredicho desvanecieran los cargos de haber cooperado a la formación de ambiente revolucionario; b) El traslado, para aquellos que siendo profesional y moralmente intachables hubieran simpatizado con partidos nacionalistas sin haber tenido participación con el comunismo; y c) La separación definitiva del servicio para los que hubieran militado o simpatizado con partidos del Frente Popular o Sociedades secretas, así como para aquellos que hubieran orientado su enseñanza o actuación profesional en el mismo sentido disolvente ${ }^{9}$.

A las puertas de la finalización del periodo bélico, por Orden 18 de marzo de 1939 , se concretan de forma concisa las sanciones, quedando divididas del siguiente modo: a) Traslado forzoso con prohibición de solicitar cargos vacantes durante un periodo de uno a cinco años; b) Suspensión de empleo y sueldo de un mes a dos años; c) Postergación desde uno a cinco años; d) Inhabilitación para el desempeño

\footnotetext{
${ }^{9}$ Boletín Oficial del Estado, 10 de diciembre de 1936, p. 360.
} 
de cargos directivos o de confianza; e) Separación definitiva del servicio. Las cuatro primeras sanciones podían imponerse aislada o conjuntamente, según las circunstancias $^{10}$.

Una vez cerrado el expediente con una propuesta de resolución (absolutoria o sancionadora), se enviaba a la Comisión de Cultura y Enseñanza donde se examinaba de nuevo y se establecía una resolución definitiva que a veces coincidía con la propuesta de la Comisión y otras no (Morente, 2001, p. 673).

Los maestros sancionados tuvieron que esperar hasta marzo de 1938 para tener la posibilidad de recurrir las sanciones impuestas. La Oficina Técnico-Administrativa (creada por orden 11 de marzo de 1938) ${ }^{11}$ se encargó de la tramitación de los expedientes, incidencias y recursos del personal docente. Un año más tarde, la Orden 18 de marzo de 1939 creaba en el Ministerio de Educación Nacional la Comisión Superior Dictaminadora, cuya misión era la revisión de los expedientes de depuración del personal dependientes de dicho Ministerio y la revisión de los fallos impuestos ${ }^{12}$.

El desenlace del proceso depurador en Segovia, que se había iniciado por el Decreto 66 de 8 de noviembre de 1936 (cuyas propuestas de sanción se iniciaron en la primavera de 1937), llegó en los meses finales de 1948. Las primeras resoluciones definitivas de maestros confirmados en sus cargos aparecieron en el BOP el 2 y el 7 de diciembre de 1938. Por su parte, las sanciones fueron publicadas en el Boletín Oficial de la Provincia el 22 de diciembre de 1939 y el 2 de febrero de 1940 (Vega, 2010, p. 346).

La depuración afectó a un total de 702 maestros segovianos ${ }^{13}$, de los cuales 184 fueron sancionados.

\section{METOdOLOGÍA}

El estudio se asienta en el paradigma cualitativo y toma el método de investigación histórico-educativo como punto de referencia para su consecución. De acuerdo con estas premisas, la investigación ha seguido las cuatro etapas clásicas de esta metodología: heurística, crítica, hermenéutica y exposición (Ruiz, 1976). Pasamos a detallar cada una de ellas.

10 Boletín Oficial del Estado, 23 de marzo de 1939, p. 1659.

${ }^{11}$ Boletín Oficial del Estado, 19 de marzo de 1938, n.o 514, p. 6324.

12 Boletín Oficial del Estado, 23 de marzo de 1939, pp. 1658-1659.

13 Según comprobaciones realizadas en el Archivo General de la Administración, en el cómputo aparecen alumnos y alumnas de la Normal de Maestros; Profesionales del Plan Profesional; Docentes que trabajaban en centros de beneficencia; maestras de párvulos; y maestros y maestras de centros públicos. 
Planteamiento de la investigación

La lectura de investigaciones previas sobre la depuración del magisterio segoviano (Dueñas y Grimau, 2004; Vega, 2002, 2004, 2010), nos llevó a percibir dos limitaciones: 1) En las publicaciones referidas se da una extensa perspectiva sobre la depuración cuantitativa del magisterio en la provincia, tendencia macrohistórica por la que se ha apostado tradicionalmente en esta línea de investigación, pero no se profundiza en exceso sobre la variable biográfica ni de género; 2) Tomando el conjunto de maestros y maestras depurados tanto de la capital como de la provincia, se ha tratado de ejemplificar algunos puntos del proceso depurador poniendo el foco de investigación en los referentes de la pedagogía segoviana de los años treinta, dejando al margen la labor de otros maestros que fueron significativos en la educación segoviana de los años cuarenta.

Estas limitaciones fueron clave para seleccionar nuestro tema de investigación, el de la depuración del magisterio segoviano entre los años 1936 y 1939. Para ello, se atiende a las variables del contexto, biografía y género, con el objetivo de adentrarnos con mayor precisión en esta temática.

\section{Fuentes}

La fuente principal que sustenta este estudio es la documentación generada por las comisiones depuradoras, que está almacenada en los expedientes de depuración de cada uno de los maestros y maestras que han sido objeto de interés para este estudio (Tabla 1). Un total de treinta y siete maestros y maestras se encontraban en activo en las escuelas públicas de la capital de Segovia al comienzo de la guerra civil.

Dichos expedientes se encuentran en la actualidad custodiados en el Archivo General de la Administración. Junto a esta fuente, hemos hecho uso también del Boletín Oficial de la Junta de Defensa Nacional de España, donde fueron publicadas las sanciones de los maestros desde el comienzo de la guerra hasta octubre de 1936, así como del Boletín Oficial del Estado y del Boletín de la Provincia de Segovia desde 1936 hasta 1940. A estas fuentes primarias se unen los datos profesionales inéditos de cada uno de estos docentes que han sido recientemente descubiertos en el Archivo Territorial de Segovia y han sido puestos a nuestra disposición para la realización de este estudio. Gracias a esta documentación conocemos los destinos de los maestros y las maestras desde el inicio de su etapa profesional, los reconocimientos obtenidos por su labor en las aulas, los puestos profesionales que ocuparon hasta su jubilación y cómo terminó su labor en la escuela. Además, contamos con documentos biográficos de cada maestro, que han sido proporcionados por el Archivo Histórico de Segovia y otros que han sido consultados en las hemerotecas de diferentes centros educativos en los que ejercieron su labor estos maestros. 
Tabla 1. Relación alfabética de maestros depurados en la capital de Segovia, cargo y centro (1936-1939)

\begin{tabular}{|c|c|c|c|}
\hline Apellidos & Nombre & Cargo & Centro educativo \\
\hline Alonso Laguna & Francisco & Maestro propietario & Grupo Escolar Colmenares \\
\hline $\begin{array}{l}\text { Álvarez } \\
\text { Matesanz }\end{array}$ & Francisco & Maestro propietario & $\begin{array}{l}\text { Graduada n. } \stackrel{1}{1} \text { de niños de la } \\
\text { Plaza de los Huertos }\end{array}$ \\
\hline Arenal Baz & $\begin{array}{l}\text { María del } \\
\text { Pilar }\end{array}$ & Directora & $\begin{array}{l}\text { Graduada n.o } 1 \text { del barrio de San } \\
\text { Lorenzo }\end{array}$ \\
\hline $\begin{array}{l}\text { Ballesteros } \\
\text { Guerra }\end{array}$ & $\begin{array}{l}\text { María } \\
\text { Amparo }\end{array}$ & $\begin{array}{l}\text { Directora interina } \\
\text { indefinida }\end{array}$ & $\begin{array}{l}\text { Escuela Graduada aneja a la } \\
\text { Normal }\end{array}$ \\
\hline Barba Sanz & Ignacio & Maestro propietario & $\begin{array}{l}\text { Graduada n. } 01 \text { de niños la Plaza } \\
\text { de los Huertos }\end{array}$ \\
\hline Benito Martín & Carlota & Maestra propietaria & $\begin{array}{l}\text { Graduada de niñas n. } 02 \text { del barrio } \\
\text { de Santa Eulalia }\end{array}$ \\
\hline $\begin{array}{l}\text { Borregón } \\
\text { Rincón }\end{array}$ & Estefanía & Maestra propietaria & $\begin{array}{l}\text { Unitaria de niñas n. } 91 \text { del barrio } \\
\text { de San Lorenzo }\end{array}$ \\
\hline $\begin{array}{l}\text { Charle de } \\
\text { Pablo }\end{array}$ & Albino & Maestro propietario & $\begin{array}{l}\text { Graduada n. } 01 \text { de niños la Plaza } \\
\text { de los Huertos }\end{array}$ \\
\hline Diez Arévalo & Teodora & Maestra propietaria & $\begin{array}{l}\text { Unitaria de niñas n. } 92 \text { del barrio } \\
\text { de San Lorenzo }\end{array}$ \\
\hline Eladio Benito & Andrés & Maestro propietario & Grupo Escolar Colmenares \\
\hline Frutos y Frutos & $\begin{array}{l}\text { Teobaldo } \\
\text { (de) }\end{array}$ & Maestro propietario & Escuela del barrio de San Lorenzo \\
\hline $\begin{array}{l}\text { Fuente } \\
\text { Moraleda }\end{array}$ & $\begin{array}{l}\text { Dolores (de } \\
\text { la) }\end{array}$ & Maestra sustituta & Escuela Práctica Graduada Aneja \\
\hline García Salinero & $\begin{array}{l}\text { María del } \\
\text { Carmen }\end{array}$ & Maestra propietaria & $\begin{array}{l}\text { Graduada de niñas n. } 02 \text { del barrio } \\
\text { de Santa Eulalia }\end{array}$ \\
\hline Gil de Bernabé & Consuelo & Maestra propietaria & $\begin{array}{l}\text { Graduada de niñas n. } 92 \text { del barrio } \\
\text { de Santa Eulalia }\end{array}$ \\
\hline González Ajo & Eulogio & Maestro propietario & Escuela del barrio de San Lorenzo \\
\hline $\begin{array}{l}\text { González de la } \\
\text { Riva Valcárcel }\end{array}$ & María & Maestra propietaria & $\begin{array}{l}\text { Graduada de niñas n. } 02 \text { del barrio } \\
\text { de Santa Eulalia }\end{array}$ \\
\hline $\begin{array}{l}\text { González } \\
\text { Delgado }\end{array}$ & José & Maestro propietario & Grupo Escolar Colmenares \\
\hline Gracia Morales & $\begin{array}{l}\text { Ángel } \\
\text { Aniceto }\end{array}$ & $\begin{array}{l}\text { Maestro } \\
\text { propietario/Director }\end{array}$ & $\begin{array}{l}\text { Graduada } n . \text { o } 1 \text { de niños la Plaza } \\
\text { de los Huertos }\end{array}$ \\
\hline
\end{tabular}


Apellidos

\begin{tabular}{|c|c|c|c|}
\hline $\begin{array}{l}\text { López de } \\
\text { Letona }\end{array}$ & $\begin{array}{l}\text { María } \\
\text { Mercedes }\end{array}$ & Maestra propietaria & $\begin{array}{l}\text { Graduada de niñas n. } 02 \text { del barrio } \\
\text { de Santa Eulalia }\end{array}$ \\
\hline López Velicia & Desiderio & Director interino & $\begin{array}{l}\text { Graduada n.o } 1 \text { de niños la Plaza } \\
\text { de los Huertos }\end{array}$ \\
\hline Martín Casado & Cipriano & Director interino & Grupo Escolar Colmenares \\
\hline $\begin{array}{l}\text { Martín } \\
\text { González }\end{array}$ & Zoila & Maestra interina & $\begin{array}{l}\text { Graduada de niñas n. } 02 \text { del barrio } \\
\text { de Santa Eulalia }\end{array}$ \\
\hline $\begin{array}{l}\text { Maseda del } \\
\text { Peso }\end{array}$ & Francisco & Maestro propietario & Grupo Escolar Colmenares \\
\hline $\begin{array}{l}\text { Moreno } \\
\text { Páramo }\end{array}$ & $\begin{array}{l}\text { María } \\
\text { Asunción }\end{array}$ & Maestra interina & $\begin{array}{l}\text { Graduada n.o } 1 \text { de niñas la Plaza } \\
\text { de los Huertos }\end{array}$ \\
\hline $\begin{array}{l}\text { Moreno } \\
\text { Velasco }\end{array}$ & $\begin{array}{l}\text { María } \\
\text { Fuencisla }\end{array}$ & Maestra propietaria & $\begin{array}{l}\text { Graduada n. } 01 \text { de niñas de la } \\
\text { Plaza de los Huertos }\end{array}$ \\
\hline Natalías García & Pedro & Director & Grupo Escolar Colmenares \\
\hline $\begin{array}{l}\text { Obejero } \\
\text { González }\end{array}$ & Carlos & Maestro propietario & $\begin{array}{l}\text { Graduada n.o } 1 \text { de niños la Plaza } \\
\text { de los Huertos de los Huertos }\end{array}$ \\
\hline Pérez Palomar & José & Maestro propietario & Grupo Escolar Colmenares \\
\hline $\begin{array}{l}\text { Ramos } \\
\text { González }\end{array}$ & Gabriel & Maestro propietario & $\begin{array}{l}\text { Graduada n.o } 1 \text { de niños la Plaza } \\
\text { de los Huertos }\end{array}$ \\
\hline Rivera Rivera & Manuel J. & Maestro propietario & Escuela del barrio de San Marcos \\
\hline $\begin{array}{l}\text { Rodríguez } \\
\text { García }\end{array}$ & Eutiquio & Maestro propietario & Grupo Escolar Colmenares \\
\hline $\begin{array}{l}\text { Sierra } \\
\text { Hernández }\end{array}$ & Vicenta & Maestra propietaria & $\begin{array}{l}\text { Graduada n.o } 1 \text { de niñas la Plaza } \\
\text { de los Huertos }\end{array}$ \\
\hline Sintes Orfila & Magdalena & Directora del centro & 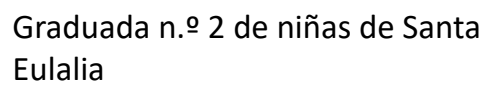 \\
\hline Tomé Villoslada, & $\begin{array}{l}\text { María } \\
\text { Asunción }\end{array}$ & Maestra sustituta & $\begin{array}{l}\text { Escuela Graduada de } \\
\text { niñas de la Casa de la Tierra }\end{array}$ \\
\hline $\begin{array}{l}\text { Valverde } \\
\text { Estebaranz }\end{array}$ & Águeda & Maestra propietaria & Escuela del barrio de San Marcos \\
\hline $\begin{array}{l}\text { Valverde } \\
\text { Estebaranz }\end{array}$ & Alejandra & Maestra propietaria & $\begin{array}{l}\text { Graduada n.o } 1 \text { de niñas la Plaza } \\
\text { de los Huertos }\end{array}$ \\
\hline $\begin{array}{l}\text { Vinuesa } \\
\text { Zamariego }\end{array}$ & Agustina & Maestra propietaria & $\begin{array}{l}\text { Escuela Graduada aneja a la } \\
\text { Normal }\end{array}$ \\
\hline
\end{tabular}


Crítica histórico-pedagógica

Una vez reunidos todos los datos, se ha procedido en primer lugar a la organización de todo el material complementario recuperado de cada docente, a la realización de una lectura pormenorizada de cada expediente y al análisis crítico del material disponible, sirviéndonos de otras fuentes sociológicas, demográficas, estadísticas y orales.

Tras la lectura del material y la crítica interna y externa de la documentación, hemos procedido a la organización de los informes por centros educativos, con el objetivo de conocer y penetrar en las relaciones establecidas entre los docentes de cada escuela. Un tercer momento nos ha llevado a analizar la información disponible atendiendo a la variable género, para intentar descubrir las diferencias entre el proceso depurador de los maestros y el de las maestras. Estas tres secuencias de análisis han sido fundamentales para poder desarrollar el análisis de los datos.

\section{Exposición de resultados}

Para la redacción de los resultados obtenidos hemos optado por estructurar la información siguiendo el orden que nos marcábamos en los objetivos específicos de la investigación. Primero trataremos de conocer los cargos a los que fueron sometidos los maestros y las maestras de la capital segoviana; después profundizaremos en las sanciones que recibieron los docentes que tuvieron algún cargo; y, por último, nos centraremos en conocer los perfiles del grupo de profesionales que no recibieron ningún tipo de sanción tras la depuración y que se convirtieron en los referentes del magisterio segoviano durante la dictadura. En este análisis tomamos la variable género como eje para la exposición de resultados y hemos optado por un estilo narrativo que profundice a través de ejemplos en los datos extraídos.

\section{ANÁLISIS DE DATOS}

\subsection{Los cargos vertidos sobre el magisterio público de la capital segoviana}

El análisis cualitativo del tipo de acusaciones que se derramaron contra el magisterio de la capital de Segovia resulta clave para conocer el modelo de docente que enseñaba en las aulas republicanas en los barrios cercanos al Acueducto. Las diferencias entre maestros y maestras ya se dejan notar en una primera evaluación de los datos que disponemos. Un total de diecisiete de los treinta y siete docentes que impartían sus enseñanzas en la capital recibieron algún tipo de 
acusación en su proceso de depuración, siendo diez hombres y siete mujeres. Los otros veinte (en su mayoría mujeres) no recibieron acusación alguna. Su sumisión a las preinscripciones de la Iglesia católica y la no participación en el movimiento e implantación de los ideales republicanos, les sirvieron de aval para mantener sus puestos profesionales.

Para profundizar en el tipo de cargos a los que se vieron sometidos esos diecisiete maestros sancionados hemos tomado como referencia la categorización que realizan Fernández y Agulló (1999a) y Ramos (2004). Antes de comenzar a analizar cada modalidad de cargos, nos gustaría mencionar las diferencias que hemos encontrado entre los expedientes masculinos y femeninos, aspecto que tomaremos como variable de partida en el análisis realizado.

\section{Cargos políticos}

Dieciséis maestros y maestras sancionados en la capital de Segovia recibieron acusaciones políticas. Entre los cargos que aparecen en esta tipología (Tabla 2), se encuentran la pertenencia a partidos integrantes del Frente Popular, la propaganda comunista, las actividades a favor de partidos de izquierdas, la simpatía con ideas izquierdistas y el entusiasmo con la causa republicana o la afiliación y militancia en partidos y organizaciones de izquierdas.

Francisco Alonso, María Fuencisla Moreno, Ángel Gracia y Carlota Benito fueron acusados por pertenecer a partidos que integraban el Frente Popular. Resulta curioso ver cómo solo cuatro de los dieciséis maestros sancionados tenían este cargo político. Quizá los expedientes más afectados por este tipo de cargo son los de los dos últimos maestros, Ángel Gracia y Carlota Benito. Al primero de ellos se le acusa de distinguirse entre sus compañeros por «su adhesión a las doctrinas del comunismo bolchevique» y por «hacer alarde de su adscripción al Frente Popular, mostrando una ambición ilimitada».

El caso de Carlota Benito es especialmente destacable, pues fue la maestra que más cargos políticos tuvo. Se le acusaba no solo de pertenecer a partidos de izquierdas, sino también de tener simpatía con ideas izquierdistas, ser entusiasta de la causa republicana y participar en el movimiento subversivo realizando actividades contra el Glorioso Movimiento Nacional. En su informe, los vecinos y maestros Desiderio López y Cipriano Martín expresaban que:

Si bien ha sido objeto de vituperio que admitiese en casa, a temporadas, a la prometida de su hijo, se ha manifestado acentuadamente frentepopulista. La buena conceptuación de que antes gozaba sufrió gran detrimento por su politicismo en estos últimos tiempos. 
Tabla 2. Cargos políticos por los que fueron acusados los maestros de Segovia capital (1936-1940)

Apellidos y nombre

Cargos políticos

Pertenece a partidos que integran el Frente Popular Es un político veleidoso

Álvarez Matesanz, Francisco

Benito Martín, Carlota

Eladio Benito, Andrés

Frutos y Frutos, Teobaldo (de)

García Salinero, María del

Carmen

González Ajo, Eulogio

González de la Riva Valcárcel, María

Gracia Morales, Ángel Aniceto

Moreno Velasco, María

Fuencisla

Natalías García, Pedro

Pérez Palomar, José

Rivera Rivera, Manuel J.

Rodríguez García, Eutiquio

Valverde Estebaranz, Águeda

Valverde Estebaranz, Alejandra

Propaganda comunista. Actividades a favor de partidos de izquierdas

Pertenece a partidos que integran el Frente Popular

Simpatía con ideas izquierdistas y entusiasta de la causa

republicana

Participar en el movimiento subversivo, realizando

actividades contra el Glorioso Movimiento Nacional

Simpatía con ideas izquierdistas y entusiasta de la causa republicana

Propaganda comunista. Actividades a favor de partidos de izquierdas. (Hizo propaganda de izquierdas en Mozoncillo). Simpatía con ideas izquierdistas y entusiasta de la causa republicana

Simpatía con ideas izquierdistas y entusiasta de la causa republicana (simpatizante del Frente Popular)

Trabajó por el Frente Popular en las elecciones de febrero

Simpatía con ideas izquierdistas y entusiasta de la causa republicana

Pertenece a partidos que integran el Frente Popular

Propaganda comunista. Actividades a favor de partidos de izquierdas

Pertenece a partidos que integran el Frente Popular

Simpatía con ideas izquierdistas y entusiasta de la causa republicana (simpatizante de partidos de extrema izquierda)

Propaganda comunista. Actividades a favor de partidos de izquierdas (propagandista del Frente Popular)

Simpatía con ideas izquierdistas y entusiasta de la causa republicana (era simpatizante del marxismo) Partidario y simpatizante del Frente Popular

Partidario y simpatizante del Frente Popular

Simpatía con ideas izquierdistas y entusiasta de la causa republicana

Simpatía con ideas izquierdistas y entusiasta de la causa republicana

Propaganda comunista. Actividades a favor de partidos de izquierdas 
Maestra abulense nacida en 1872, Carlota Benito obtuvo su título de Magisterio con nota sobresaliente en septiembre de 1896. Cuando fue depurada tenía 64 años y llevaba en activo cuarenta. Durante su vida profesional había trabajado en escuelas en Cáceres, Valladolid, Palencia, Burgos y Segovia y en todas ellas había recibido el reconocimiento a su labor al frente de la escuela. En el pliego de descargos, redactado por el abogado Alfredo Nieto, quien escribió un informe detallado exculpatorio; y avalado por Sor María Juana de Santa Teresa, carmelita descalza del convento de Ávila; y Vicente Fernández Álvarez, religioso marista, exdirector del colegio de los Hermanos Maristas de Segovia, la maestra exponía que: «No son ciertas todas inculpaciones. Mi conducta ha sido la que corresponde a una persona de convicciones religiosas e identificada con las ideas de la causa nacional», pero las acusaciones le llevaron a la separación definitiva de la profesión docente, igual que a su compañera María Fuencisla Moreno.

El cargo político imputado al maestro Francisco Alonso carece de veracidad, pues en su expediente se demuestra que no había estado afiliado a ningún partido, hecho que corroboran sus compañeros Desiderio López y Cipriano Martín en su informe, pero se le impone este cargo porque estos mismos compañeros defienden que «aunque no haya estado afiliado a ningún partido, ha patentizado su izquierdismo acudiendo a las manifestaciones públicas socialistas, incluso a la del 1 de mayo de 1936».

Las manifestaciones públicas de apoyo a la causa republicana llevaron a otros compañeros como Teobaldo de Frutos, Alejandra Valverde, Águeda Valverde, Eutiquio Rodríguez, Manuel J. Rivera, Pedro Natalías, María González, María del Carmen García, Andrés Eladio Benito a ser acusados de simpatizar con ideas izquierdistas y ser entusiastas de la causa republicana. Este cargo político fue el que afectó al mayor número de maestros y por el que fueron acusadas también varias maestras. Comprobando los expedientes de todos ellos puede verse cómo solía ser el alcalde el encargado de delatar la simpatía de los maestros por esta ideología sin fundamentar demasiado sus argumentos, como ocurre en el caso de Alejandra y Águeda Estebaranz y María del Carmen García, que se habla de sus ideas marxistas y de su apoyo al Frente Popular sin exponer acciones concretas. En el caso de María González, fue el Gobernador Civil quien decía de ella:

La señora maestra daba baja por el Ex. Sr. Gobernador Civil por sus ideas izquierdistas. De ideas muy avanzadas según es público en Segovia, tiene en su casa 2 niñas que dice son sus sobrinas que parece que se jactan frecuentemente de su irreligión, asegurando a otras niñas y a personas mayores que no hay Dios y otros desatinos por el estilo, "porque lo dice su tía». Es completamente laica, pues hace alarde que su hijo ya de 11 años no había confesado y decía que eran tonterías. Iba a la casa del pueblo a enseñar a cantar «los pioneros». 
Resulta destacable como esta acusación no le sirvió para tener cargos religiosos, sino políticos y ser separada del servicio durante todo el periodo de la guerra.

En el caso de los hombres, no fueron las acusaciones del alcalde y el gobernador civil las que fueron clave para su delación, sino los informes de los vecinos y maestros Desiderio López y Cipriano Martín, que acusaron a sus compañeros de su simpatía por la izquierda. De Pedro Natalías y Manuel J. Rivera decían que eran simpatizantes del marxismo (el primero más peligroso que el segundo, porque le tachaban de ser simpatizante de la extrema izquierda). A Teobaldo de Frutos le catalogaban como «católico insincero, hipócrita, aprovechado e ingrato. De aparentes ideas derechistas desde que está en Segovia, pero de fondo izquierdista». Como su compañero Eutiquio Rodríguez, considerado simpatizante con los ideales de la izquierda; y Andrés Eladio Benito, que le tacharon de izquierdista porque un compañero de la capital, durante los años de la II República, se presentó como candidato a diputado a Cortes por el partido socialista y le pidió su voto.

Muchos fueron los que tuvieron algún tipo de sanción relacionada con la propaganda comunista y las actividades a favor de partidos de izquierdas, como es el caso de Francisco Álvarez, Teobaldo de Frutos, María Fuencisla Moreno, José Pérez y Alejandra Valverde. Teobaldo de Frutos fue acusado por haber hecho en el pueblo de Mozoncillo, donde ejerció su cargo como maestro antes de ser destinado a la capital segoviana, labor de proselitismo izquierdista. De José Pérez, el Gobernador Civil señala que era un «maestro de ideas marxistas. Incondicional y muy identificado con Pedro Natalías. Algún tiempo debió pertenecer a Izquierda Republicana, pero desde luego es de izquierdas». En el pliego de descargos que realiza este maestro puede verse la audacia con la que defiende su indiferencia hacia la política explicando que:

Todavía recuerdo que una vez propuse a los compañeros, testigo de ello es D. José González, maestro del Grupo Escolar Colmenares, tener una reunión con los padres de familia, a fin de que los niños no tomasen partido en ninguna manifestación ni acto político, ya que esto se deja para los mayores y desgraciadamente en nuestro Grupo Escolar ya se dejaba sentir esta contrariedad. Creo que, si hubiera sido propagandista del Frente Popular, habría dejado a los niños seguir su marcha hacia el abismo.

Los maestros sabían que en su pliego de descargos estaba en juego no solo su puesto de trabajo sino su situación económica, pues la depuración implicaba la pérdida de su empleo y la dificultad para encontrar un nuevo trabajo alejado de la docencia. Como explica Vega (2010), esta angustiosa situación hacía que algunos docentes expedientados expresaran sumisión ante las autoridades y escribieran lo que las comisiones depuradoras querían oír, para intentar cambiar su destino.

De las dos maestras delatadas por su participación en partidos de izquierdas realizando propaganda y actividades a favor de los mismos, puede comprobarse la 
falta de veracidad de dichas sanciones. María Fuencisla Moreno fue destacada en este cargo gracias al sacerdote, que exponía la participación de la citada maestra en las manifestaciones del uno de mayo y especialmente por haber acudido a la última de estas manifestaciones, en 1936. De Alejandra Valverde solo se destaca por parte del alcalde su apoyo "al mal llamado Frente Popular», sin mencionar en qué consistía dicho apoyo.

De los expedientes de todos ellos en este punto, el más reseñable es el de Francisco Álvarez. En el informe que realiza el alcalde de Segovia, Andrés Reguera Antón, sobre el citado maestro puede leerse como le cataloga como «una de las principales figuras comunistas de la capital». El cura, Pedro Gozalo, sin ningún tipo de prueba, delataba al maestro en su informe exponiendo que «al estallar el movimiento revolucionario se fugó, según noticias de esta capital, se supone que marchó a Madrid, para ofrecerse al gobierno como partidario del mismo y socio activo y cooperador». Además, Francisco Álvarez fue el único de los maestros referidos acusado por el Gobernador Civil de ser afecto a la Casa del Pueblo durante el periodo republicano. Esta acusación resulta importante si pensamos que durante este periodo las Casas del Pueblo no solo eran los domicilios de las sociedades obreras, en las que se llevan a cabo actividades administrativas y societarias, sino que acogían nuevas formas de sociabilidad cultural y orgánica (Caro, 2015).

Todos los maestros que pudieron trataron de desmentir en sus pliegos de descargos las acusaciones políticas que les habían sido impuestas, pues sabían que junto a las sindicales y religiosas, iban a suponer serios problemas para volver a la enseñanza. Muchos desmentían la acusación, otros las negaban presentando su sorpresa ante tales acusaciones (como era mayoritariamente el caso de las mujeres) y un tercer grupo, los menos, las aceptaban, alegando que eran por causa obligada.

\section{Cargos sindicales}

El Gobernador Delegado de la Autoridad Militar, Joaquín España Cantos, publicaba el 13 de agosto de 1936 una Circular en el Boletín Oficial de la Provincia con la relación de 74 maestros (de los cuales 8 eran maestras), que habían sido cesados a finales de julio por su afiliación a la Asociación de Trabajadores de la Enseñanza en la provincia de Segovia. En esta lista aparece el nombre de los cinco maestros y cuatro maestras que les fueron imputados cargos sindicales en la capital de Segovia: Francisco Álvarez Matesanz, Carlota Benito Martín, María González de la Riva Valcárcel, Ángel Gracia Morales, María Fuencisla Moreno Velasco, José Pérez Palomar, Manuel J. Rivera Rivera, María Visitación Tomé Villoslada y Pedro Natalías García. Este último era secretario de la Asociación Provincial del Magisterio.

La presencia del sindicato de Trabajadores de la Enseñanza fue decisiva para la mejora de la enseñanza durante el periodo de la II República y también fue clave 
su papel en el frente y la retaguardia. Como explica Ramos (2004) la participación de los maestros en los sindicatos representaba no solo la implicación del maestro en la política del gobierno republicano, sino también su compromiso activo con los partidos de izquierdas, por ello las comisiones depuradoras tomaron especial recelo en acusar a los maestros sindicados.

Ninguno de los maestros acusados estuvo afiliado a otro sindicato que no fuera el de la UGT. Sin embargo, las cifras que se presentan entre hombres y mujeres nos llevan a deducir que la participación de las maestras en los sindicatos profesionales era menor que la de los maestros. Analizando los comentarios cualitativos que aparecen en los expedientes vemos cómo los hombres eran más activos que las mujeres. Así, José Pérez y Francisco Álvarez fueron acusados por asistir a los actos que proponía FETE y cooperar activamente con este sindicato. En el caso de las maestras no se explica cuál era su participación real.

\section{Cargos religiosos}

Si hablamos de cargos religiosos, la cantidad de cargos de esta índole se atribuyen exclusivamente a los maestros masculinos de la capital. Francisco Alonso Laguna, Francisco Álvarez Matesanz, Andrés Eladio Benito, Ángel Gracia Morales, Pedro Natalías García y José Pérez Palomar fueron acusados por no profesar religión católica y hacer visibles conductas irreligiosas. El Nuevo Estado quería asegurar la limpieza en las escuelas de cualquier elemento contrario a la Iglesia católica (Ramos, 2005, p. 140), por eso no dudaron en informar negativamente sobre aquellos docentes contrarios al catolicismo.

En el caso de la capital segoviana, el arraigo del catolicismo en la región favoreció que ninguna mujer fuera imputada por este tipo de cargos. En los expedientes de depuración femeninos, a pesar de que se informa de cómo algunas maestras se encontraban apartadas de las clases religiosas, como María del Carmen García Salinero o María Visitación Tomé Villoslada; o no asistían públicamente a los actos religiosos, como se informa en el expediente de María Fuencisla Moreno, se justifica su falta de participación en este tipo de actos a la situación política previa o a los hombres con los que se relacionaba a la maestra:

Doña Fuencisla Moreno Velasco, viuda de Ángel Gracia, que se encuentra ahora en Segovia, durante su permanencia en el pueblo de Valverde del Majano y antes de contraer matrimonio, cumplió debidamente con sus obligaciones como cristiana (Matías Gilarranz. Cura de Valverde del Majano, 9 de noviembre de 1936).

Esta situación es una prueba más de cómo el franquismo consideraba a la mujer como una persona manipulable y subordinada al patriarcado, pero a la vez deja al descubierto cómo las maestras contrarias al Régimen no lo estaban a los principios 
de la moral católica, pues en ningún caso se muestran en sus expedientes malas conductas religiosas ni comportamientos contrarios a la religión católica.

Sí se presentan, en cambio, este tipo de comportamientos en el caso de los hombres. Por ejemplo, en el expediente del maestro Ángel Gracia Morales (marido de la maestra María Fuencisla Moreno), el sacerdote de la parroquia del Salvador informa que:

Siendo feligrés de esta parroquia de San Martín, dio a luz su mujer y aunque con alguna repugnancia, según noticias, consintió que su hija fuera bautizada. No se dignó a hacer acto de presencia ni en el acto de Bautizo ni antes en el despacho parroquial, designando como padrinos a la criada y a un joven estudiante y pupilo en su casa (6 de mayo de 1937).

La falta de asistencia a la parroquia también es motivo de informe negativo para el maestro Francisco Álvarez Matesanz. El cura, Pedro Gozalo, dice en su informe que:

Desde que contrajo matrimonio, jamás solía vérsele por la iglesia ni aún para cumplir lo prometido en el acto de contraer matrimonio o velarse en el tiempo fijado por la Iglesia (6 de mayo de 1937).

Asimismo, del maestro Andrés Eladio Benito se decía que tampoco solía frecuentar la parroquia del barrio. Sí lo hacía en cambio el maestro Francisco Alonso Laguna, a pesar de que los vecinos y maestros Desiderio López y Cipriano Martín en 1937 le caracterizaban como «persona acomodaticia que al propio tiempo que pone una vela a Dios, coloca al diablo, para estar a bien con los dos».

José Pérez Palomar, también es tachado de irreligioso y además en su expediente se explica que era una persona incondicional y muy identificada con Pedro Natalías. Este último maestro fue tachado de irreligioso no solo por su ausencia a las liturgias religiosas, sino por las prácticas que llevaba a cabo en el centro del que él era su director. En las actas de la sociedad de Amigos de la Escuela del Colmenares, con fecha 23 de enero de 1932, se explica cómo Natalías retiró de la escuela todos los símbolos de la religión, actos que no fueron del todo bien recibidos por un grupo de maestros de la escuela ni tampoco por la sociedad segoviana. Así puede comprobarse en la noticia de El Adelantado de Segovia con fecha 20 de enero de 1932, titulada "Un caso poco educativo ocurrido en el grupo escolar Colmenares» donde en director tomó en su mano un crucifijo y le pidió a un alumno que lo echara a la caldera, ante la mirada repugnada de otro maestro que presenció el acto. El maestro Cipriano Martín denunció a Natalías por esta acción. Desde la inspección, José Luis Jaume, abrió una investigación para esclarecer los hechos ocurridos que concluyó demostrando la absoluta falsedad de lo denunciado en prensa (Dueñas, 2014, p. 63). 


\section{Cargos culturales y humanitarios}

Dos fueron los maestros de la capital de Segovia que tuvieron cargos humanitarios. A Francisco Álvarez Matesanz y a Ángel Gracia Morales se les acusó de ser cotizantes pro-familias de los presos de 1934. La solidaridad con las víctimas políticas de la represión ejercida por las fuerzas reaccionarias en 1934, por la experiencia revolucionaria de los mineros de Asturias (Piemonte, 2014), agravó el expediente de algunos maestros que habían contribuido con la causa. Este tipo de acciones fueron consideradas como un apoyo político hacia la causa republicana, pues significaron un hecho trascendente en la historia de la lucha de clases en España y en las relaciones entre la derecha y la izquierda, que desembocaron años más tarde en la Guerra Civil (Carr, 1985, p. 41).

Pero además de los cargos culturales, también fueron motivo de sanción las actividades culturales e intelectuales, en las que igual que las humanitarias, como hemos podido comprobar, solo fueron hombres los que se vieron acusados de ellas.

En este tipo de cargos se destacan la lectura de prensa izquierdas, acción que fue motivo de sanción para Manuel J. Rivera Rivera; la colaboración en prensa con artículos considerados contrarios a los valores nacionalcatólicos, como ocurrió a Francisco Alonso Laguna; y en el peor de los casos, la dirección de prensa, como fue el caso de Ángel Gracia.

Ángel Gracia fue uno de los maestros más renovadores de la provincia de Segovia. Natural de Becerril de la Sierra (Madrid), obtuvo su título de maestro el 8 de noviembre de 1913. Entre 1918 y 1931 fue maestro en las escuelas segovianas de Boceguillas y Cantalejo. Después tomó posesión en la escuela de Cercedilla el 15 de enero de 1931 y en ese mismo año, a finales de julio, fue trasladado a la escuela graduada número 1 de Segovia, sita en la Plaza de los Huertos. Durante su trayectoria profesional se le concedieron varios votos de gracias, por considerarle un maestro inteligente, emprendedor, laborioso y ejemplar; premios al mérito en varios concursos escolares e incluso la medalla de bronce de la Mutualidad Escolar por los servicios prestados, el 26 de noviembre de 1925. Gracia fue además pensionado por la JAE el 5 de octubre de 1929 para la realización de estudios en Francia, Bélgica y Suiza.

En 1932 fundó junto con Julio Fuster y Pedro Natalías el periódico Escuela Segoviana. Semanario de enseñanza, de carácter profesional, que nació el 7 de enero de 1932, fue dirigido por el maestro Julio Fuster, docente comprometido con el impulso pedagógico republicano y destacado miembro de la Asociación de maestros Interinos, de la Asociación de Trabajadores de la enseñanza y de la Unión de Maestros Españoles (Moreno, 2019, p. 217). El comité de redacción del periódico «Escuela Segoviana» estaba compuesto por Natalías y Gracia, aunque de los dos maestros solo este último fue acusado por el Gobernador Civil de su participación en dicha publicación. Este semanario se publicaba todos los jueves y trataba temas vinculados con la educación (Sáez, 1940). Cesó su actividad el 16 de julio de 1936. 
Francisco Alonso Laguna, otro de los maestros acusados con este cargo, escribió un artículo titulado Sinceridad en el número 2013 de este mismo periódico (Figura 1). Por este hecho fue sancionado, al considerar la comisión depuradora que el maestro apoyaba la labor de la República en materia política y educativa.

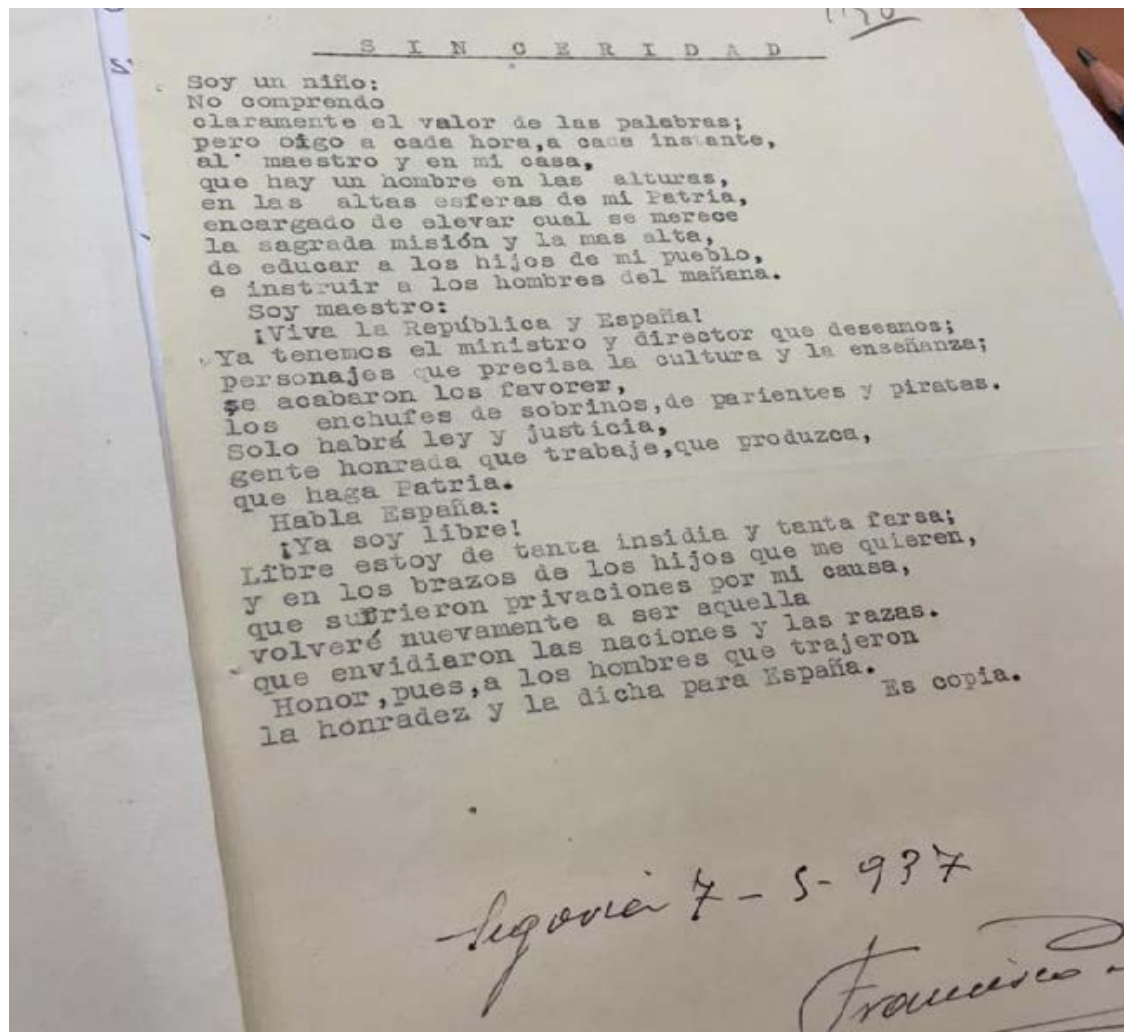

Figura 1. Artículo Sinceridad (Escuela Segoviana), n.o 2013.

En el pliego de descargos, el maestro aludía a que en el artículo explicaba su gratitud por el beneficio obtenido al elevar los sueldos del magisterio y por el aumento del número de escuelas, palabras que no fueron suficientes para eludir sanciones.

\section{Cargos morales}

Solo a dos de los maestros segovianos sancionados se les imputan cargos morales. Es el caso de Pedro Natalías García y Águeda Valverde Estebaranz. Del primero de ellos se destaca en su informe su inmoralidad. Sus compañeros de profesión, Desiderio López y Cipriano Martín, no dudan en acusarle de tolerar en los escolares 
que había tenido a su cargo «irrespetuosidad a las personas y cosas elevadas». Cipriano Martín había compartido con Natalías centro a lo largo de la década de 1930 y había visto el reproche social al que fue sometido por retirar del grupo escolar Colmenares los símbolos de la religión, pero, además, conocía su labor como vocal y secretario del Consejo Provincial de Primera Enseñanza habiendo ofrecido su apoyo a las Misiones Pedagógicas y sabía de su participación en los Congresos Pedagógicos de Segovia, en los que el maestro no dudaba en exponer su desacuerdo con la enseñanza tradicional. Como afirma Dueñas (2014) algunos no perdonaron a los maestros renovadores su posicionamiento y compromiso con el pueblo.

A Águeda Valverde se le acusaba de ofrecer mal ejemplo por su conducta social. Casada con un sacerdote carmelita segoviano, el cura y el alcalde en sus informes decían de ella que dejaba mucho que desear en su conducta privada, así como la oficial en la escuela, por convertirse en un mal ejemplo para sus alumnas por su modo de vivir "no del todo claro». Precisamente este hecho lleva a las autoridades a tachar a esta maestra como una mujer de "conducta de peligrosa y escandalosa» que debía ser expulsada del cuerpo docente por esta acción que transgredía el orden moral.

Con los ejemplos de estos dos maestros puede comprobarse cómo el franquismo perseguía y castigaba a aquellos docentes que habían aprovechado las libertades republicanas para cuestionar el papel de la religión en la escuela y el modelo tradicional de mujer. No en vano, como explica Onandia (2019) la misión del Régimen desde el final de la contienda no fue otra que preservar la religión católica y la nación española de la llamada «inmoralidad social» que se había expandido sin control por todo el territorio en la década anterior, aspecto que se tuvo muy en cuenta en los expedientes de depuración de los maestros.

\section{Cargos profesionales}

Pedro Natalías García también fue cuestionado por su labor profesional, junto a Eutiquio Rodríguez García. Al primero, los dos maestros de la comisión depuradora segoviana del magisterio le acusaban de «haber tolerado en los escolares manifestaciones de puños en alto». También fueron ellos, Desiderio López Velicia y Cipriano Martín Casado, los que a Eutiquio Rodríguez no dudaron en acusarle de ser «tolerante con los pequeños en las actitudes propias del frente-populismo». Como puede comprobarse, la propagación en la escuela de ideas vinculadas con el comunismo y el socialismo solo fueron atribuidas a los maestros masculinos. En los expedientes de las maestras apreciamos que, a pesar de los cargos imputados, se destaca de ellas su cumplimiento con los deberes profesionales y sus buenas costumbres religiosas dentro del aula. En ningún caso se habla de actitudes políticas de las maestras dentro del aula, un aspecto que encierra cierta lógica si pensamos en su reducida participación en este campo. 


\subsection{Las sanciones a las que se vieron sometidos los maestros y maestras}

Tras la revisión de los informes presentados por las Comisiones depuradoras, los docentes recibieron las correspondientes sanciones (Tabla 3). A pesar de que el número de maestros y maestras de la capital habilitados fue superior al de castigados, la represión del proceso depurativo afectó a todos ellos. Como destacan Fernández y Agullo (1999b), el buen maestro era aquel que reunía las cualidades de patriota y católico, por encima de su buena formación y práctica pedagógica, por ello, cualquier docente que no respondiera a estas características debía ser sancionado (p. 265).

Tabla 3. Sanciones recibidas por los maestros de Segovia capital (1936-1940)

\begin{tabular}{|c|c|c|c|c|}
\hline $\begin{array}{l}\text { Apellidos y } \\
\text { nombre }\end{array}$ & Sanción inicial & Fecha & Sanción definitiva & Fecha \\
\hline $\begin{array}{l}\text { Alonso } \\
\text { Laguna, } \\
\text { Francisco }\end{array}$ & $\begin{array}{l}\text { Nueve meses de } \\
\text { suspensión de } \\
\text { empleo y sueldo e } \\
\text { inhabilitación para } \\
\text { el desempeño de } \\
\text { cargos directivos y } \\
\text { de confianza. }\end{array}$ & 15/06/1937 & $\begin{array}{l}\text { Suspensión de empleo } \\
\text { y sueldo e inhabilitación } \\
\text { para el ejercicio de } \\
\text { cargos directivos y de } \\
\text { confianza. }\end{array}$ & $30 / 03 / 1939$ \\
\hline $\begin{array}{l}\text { Álvarez } \\
\text { Matesanz, } \\
\text { Francisco }\end{array}$ & Cesado & $14 / 08 / 1936$ & $\begin{array}{l}\text { Separación definitiva } \\
\text { del servicio y baja en el } \\
\text { escalafón }\end{array}$ & $30 / 03 / 1939$ \\
\hline $\begin{array}{l}\text { Benito } \\
\text { Martín, } \\
\text { Carlota }\end{array}$ & $\begin{array}{l}\text { Separación } \\
\text { del servicio e } \\
\text { inhabilitación para } \\
\text { el desempeño de } \\
\text { cargos directivos y } \\
\text { de confianza }\end{array}$ & 26/08/1936 & $\begin{array}{l}\text { Separación definitiva del } \\
\text { servicio }\end{array}$ & $02 / 02 / 1940$ \\
\hline $\begin{array}{l}\text { Eladio } \\
\text { Benito, } \\
\text { Andrés }\end{array}$ & $\begin{array}{l}\text { Suspensión de } \\
\text { empleo y sueldo }\end{array}$ & 22/12/1939 & $\begin{array}{l}\text { Traslado fuera de } \\
\text { la provincia, con } \\
\text { prohibición de solicitar } \\
\text { puestos vacantes } \\
\text { durante } 5 \text { años e } \\
\text { inhabilitación para } \\
\text { ocupar cargos directivos } \\
\text { y de confianza }\end{array}$ & $7 / 10 / 1940$ \\
\hline
\end{tabular}




\begin{tabular}{|c|c|c|c|c|}
\hline $\begin{array}{c}\text { Apellidos y } \\
\text { nombre }\end{array}$ & Sanción inicial & Fecha & Sanción definitiva & Fecha \\
\hline $\begin{array}{l}\text { Frutos y } \\
\text { Frutos, } \\
\text { Teobaldo } \\
\text { (de) }\end{array}$ & $\begin{array}{l}\text { Continuación en } \\
\text { el servicio sin } \\
\text { pronunciamientos } \\
\text { favorables }\end{array}$ & $15 / 06 / 1937$ & & \\
\hline $\begin{array}{l}\text { García } \\
\text { Salinero, } \\
\text { María del } \\
\text { Carmen }\end{array}$ & $\begin{array}{l}\text { Continuación en } \\
\text { el servicio sin } \\
\text { pronunciamientos } \\
\text { favorables }\end{array}$ & 15/10/1937 & & \\
\hline $\begin{array}{l}\text { González } \\
\text { Ajo, Eulogio }\end{array}$ & $\begin{array}{l}\text { Continuación en } \\
\text { el servicio sin } \\
\text { pronunciamientos } \\
\text { favorables }\end{array}$ & $15 / 06 / 1937$ & & \\
\hline $\begin{array}{l}\text { González } \\
\text { de la Riva } \\
\text { Valcárcel, } \\
\text { María }\end{array}$ & $\begin{array}{l}\text { Separación definitiva } \\
\text { del servicio e } \\
\text { inhabilitación para } \\
\text { el desempeño de } \\
\text { cargos directivos y } \\
\text { de confianza }\end{array}$ & 15/10/1937 & $\begin{array}{l}\text { Suspensión de empleo } \\
\text { y sueldo con traslado } \\
\text { fuera de la provincia. } \\
\text { Prohibición para } \\
\text { solicitar cargos vacantes } \\
\text { durante cinco años e } \\
\text { inhabilitación } \\
\text { para el ejercicio de } \\
\text { cargos directivos y de } \\
\text { confianza }\end{array}$ & $30 / 03 / 1939$ \\
\hline Gracia & & & $\begin{array}{l}\text { Separación definitiva del } \\
\text { servicio e inhabilitación }\end{array}$ & \\
\hline $\begin{array}{l}\text { Morales, } \\
\text { Ángel }\end{array}$ & Cesado & 14/08/1936 & $\begin{array}{l}\text { para el desempeño de } \\
\text { cargos directivos y de } \\
\text { confianza }\end{array}$ & 20/05/1937 \\
\hline $\begin{array}{l}\text { Moreno } \\
\text { Velasco, } \\
\text { María } \\
\text { Fuencisla }\end{array}$ & $\begin{array}{l}\text { Separación definitiva } \\
\text { del servicio e } \\
\text { inhabilitación para } \\
\text { el desempeño de } \\
\text { cargos directivos y } \\
\text { de confianza }\end{array}$ & 20/05/1937 & & \\
\hline $\begin{array}{l}\text { Natalías } \\
\text { García, } \\
\text { Pedro }\end{array}$ & Cesado & 14/08/1936 & $\begin{array}{l}\text { Separación definitiva } \\
\text { del servicio y baja en el } \\
\text { escalafón respectivo }\end{array}$ & $30 / 03 / 1939$ \\
\hline
\end{tabular}




\begin{tabular}{|c|c|c|c|c|}
\hline $\begin{array}{l}\text { Apellidos y } \\
\text { nombre }\end{array}$ & Sanción inicial & Fecha & Sanción definitiva & Fecha \\
\hline $\begin{array}{l}\text { Pérez } \\
\text { Palomar, } \\
\text { José }\end{array}$ & Cesado & $31 / 08 / 1936$ & $\begin{array}{l}\text { Suspensión de empleo y } \\
\text { sueldo. Traslado forzoso } \\
\text { dentro de la provincia } \\
\text { con prohibición de } \\
\text { solicitar cargos vacantes } \\
\text { durante } 5 \text { años e } \\
\text { inhabilitación para } \\
\text { el ejercicio de cargos } \\
\text { directivos y de confianza }\end{array}$ & $30 / 03 / 1939$ \\
\hline $\begin{array}{l}\text { Rivera } \\
\text { Rivera, } \\
\text { Manuel J. }\end{array}$ & $\begin{array}{l}\text { Alejamiento de la } \\
\text { función docente por } \\
\text { un periodo de dos } \\
\text { años. Suspensión } \\
\text { de empleo y sueldo } \\
\text { e inhabilitación } \\
\text { para ocupar cargos } \\
\text { directivos y de } \\
\text { confianza }\end{array}$ & 20/05/1937 & $\begin{array}{l}\text { Suspensión de empleo } \\
\text { y sueldo. Inhabilitación } \\
\text { para el ejercicio de } \\
\text { cargos directivos y de } \\
\text { confianza y traslado } \\
\text { forzoso fuera de } \\
\text { la provincia, con } \\
\text { prohibición de solicitar } \\
\text { cargos vacantes durante } \\
5 \text { años }\end{array}$ & $30 / 03 / 1939$ \\
\hline $\begin{array}{l}\text { Rodríguez } \\
\text { García, } \\
\text { Eutiquio }\end{array}$ & $\begin{array}{l}\text { Continuación en el } \\
\text { servicio }\end{array}$ & 15/06/1937 & & \\
\hline $\begin{array}{l}\text { Tomé } \\
\text { Villoslada, } \\
\text { María } \\
\text { Asunción }\end{array}$ & $\begin{array}{l}\text { Inhabilitación para } \\
\text { el desempeño de } \\
\text { cargos directivos y } \\
\text { de confianza. } \\
\text { Separación definitiva } \\
\text { del servicio }\end{array}$ & 15/06/1937 & $\begin{array}{l}\text { Inhabilitación perpetua } \\
\text { para desempeñar en } \\
\text { escuelas }\end{array}$ & $30 / 03 / 1939$ \\
\hline $\begin{array}{l}\text { Valverde } \\
\text { Estebaranz, } \\
\text { Águeda }\end{array}$ & $\begin{array}{l}\text { Separación definitiva } \\
\text { del servicio e } \\
\text { inhabilitación para } \\
\text { el desempeño de } \\
\text { cargos directivos y de } \\
\text { confianza. Baja en el } \\
\text { escalafón }\end{array}$ & $15 / 10 / 1937$ & $\begin{array}{l}\text { Separación definitiva } \\
\text { del servicio y baja en el } \\
\text { escalafón }\end{array}$ & $30 / 12 / 1939$ \\
\hline $\begin{array}{l}\text { Valverde } \\
\text { Estebaranz, } \\
\text { Alejandra }\end{array}$ & $\begin{array}{l}\text { Separación definitiva } \\
\text { del servicio e } \\
\text { inhabilitación para } \\
\text { el desempeño de } \\
\text { cargos directivos y } \\
\text { de confianza }\end{array}$ & 15/10/1937 & $\begin{array}{l}\text { Separación definitiva } \\
\text { del servicio y baja en el } \\
\text { escalafón }\end{array}$ & $30 / 12 / 1939$ \\
\hline
\end{tabular}


De la lista de maestros y maestras anteriormente expuesta, merecen especial atención los maestros Pedro Natalías y Ángel Gracia, que fueron fusilados. En el expediente de depuración del primero de ellos, aparece el 24 de marzo de 1937 un informe del Gobernador Civil en el que se puede leer «D. Pedro Natalías García. Maestro propietario de Segovia (fusilado)». La realidad es que ni siquiera pudo leer la primera de las sanciones impuestas, pues en julio de 1936 fue detenido y estuvo preso en la cárcel de Segovia hasta que fue asesinado en la "saca» de presos que tuvo lugar el 15 de agosto de 1936. Como se destaca en Sonlleva y Sanz (2017) sus únicos delitos fueron amar su profesión y tener inquietudes pedagógicas.

En cuanto al segundo de los maestros, Ángel Gracia, fue detenido pocos días antes de terminar la guerra. Después de permanecer 34 días en la cárcel de Segovia, fue asesinado por ejecución extrajudicial en Puente Oñez (Anaya), el 28 de julio de 1936. El maestro tenía 42 años y tres hijos. Su viuda, la maestra María Fuencisla Moreno, separada definitivamente del servicio en 1937 (a pesar de haber presentado un extenso pliego de descargos repleto de firmas de apoyo que avalaban su labor en la escuela), quedó en la más absoluta miseria. En cuanto a las peticiones de ayuda que pidió a las instituciones y a la Iglesia, todas ellas le fueron denegadas por su vinculación con el partido comunista y su falta de participación en actos religiosos. Un cáncer de pecho terminó con su vida el 23 de marzo de 1937 (Moreno, 2019 , p. 389). Lo mismo ocurrió con María Visitación Tomé, que conceptuada como mujer de tendencias izquierdistas y corruptora de la conciencia de los niños, fue separada del servicio de forma perpetua al finalizar la Guerra Civil

Otros maestros como Francisco Álvarez Matesanz, Carlota Benito Martín, Águeda Valverde Estebaranz y Alejandra Valverde Estebaranz también sufrieron como Fuencisla Moreno las consecuencias de la depuración, pues fueron separados definitivamente del servicio entre 1939 y 1940. De Carlota Benito se sabe que inició un recurso en 1939, pero hasta 1942 no fue admitida la revisión. Se reconoció que no había sido escuchada:

Considerando que, si bien la jubilación de la Sra. Benito por razón de edad no permite su reintegro al Magisterio Nacional, si así se acordase, no por eso debe prescindirse de llevar a cabo la revisión solicitada, ya que esta puede modificar un pronunciamiento tan desfavorable como el que pesa sobre esta maestra, dictado en la resolución de su expediente de depuración sin que hubiese sido oída en descargos.

Formuló un pliego de descargos de nuevo en 1943 y consiguió una revisión de su expediente, quedando suspendida esta vez de empleo y sueldo e inhabilitada para cargos de confianza.

En este tiempo se fue a residir a Oviedo, donde le fue concedida la jubilación forzosa el 17 de junio de 1944, a sus setenta años. La maestra, a pesar de estar jubilada, quiso limpiar su honor y pidió a mediados de la década de 1940 una revisión 
de su expediente. En el informe dictado por el Juzgado Superior el 28 de abril de 1945 puede leerse:

Atenuados los cargos que en su día se hicieron, no se desvirtúa totalmente su izquierdismo ni su afiliación a Trabajadores de la Enseñanza (...). Cabe anular la sanción gravísima, pero no debe quedar sin ninguna sanción que corresponda a sus antecedentes izquierdistas.

Finalmente, se le retira el informe sancionador inicial, a pesar de que se indica que el Estado no puede retractarse y reconocer un error en su dictamen: «Ni menos podría declararse el error evidente de la Administración que permitiera aconsejar el abono de los haberes no percibidos». Se mantuvo así la última de las sanciones recibidas.

Los casos de las maestras citadas nos permiten corroborar cómo la implicación activa de aquellas docentes que se atrevieron a participar en cuestiones políticas fue más duramente castigada que en los maestros, quienes tradicionalmente y por excelencia llevaban décadas acaparando todo el protagonismo en la esfera pública (Ramos, 2005, p. 130).

La sanción para otros maestros como Francisco Alonso Laguna, Andrés Eladio Benito, María González de la Riva Valcárcel, José Pérez Palomar y Manuel J. Rivera Rivera fue la suspensión de empleo y sueldo, el traslado forzoso dentro o fuera de la provincia, la prohibición de solicitar cargos vacantes durante 5 años y la inhabilitación para el ejercicio de cargos directivos y de confianza. El primero de ellos, tras volver a solicitar una revisión de su expediente, volvió a impartir sus enseñanzas como maestro en el Grupo Escolar Colmenares (por entonces ya bautizado el centro con el nombre de «Primo de Rivera»), donde llevaba desempeñando su labor desde el año 1931.

En el expediente de María González de la Riva puede leerse en la sanción final los destinos a los que la maestra podía pedir su traslado. Las ciudades mencionadas para tal fin fueron: Sevilla, Málaga, Granada, Ceuta o Tetuán, lugares alejados de la capital segoviana.

José Pérez Palomar, maestro del Grupo Escolar Colmenares, reclama las sanciones impuestas y el 23 de abril de 1940, el Ministerio accede a la petición de revisar su expediente de nuevo tras aportar el segundo pliego de descargos -el 19 de diciembre de 1939- en el que explica:

1. Quedo muy sorprendido por haber sido trasladado de provincia, pues me dediqué expresamente a la escuela.

2. La plaza de la escuela en la que desempeño mi labor y de la que me quieren trasladar, la obtuve por méritos según Orden Ministerial 1 de julio de 1934 y mi labor en ella fue siempre del más alto espíritu patriótico, según relatan los informes de familia. 
3. Mi adhesión al Glorioso Movimiento Nacional está fuera de dudas por las aportaciones que hice a las suscripciones del Movimiento. Además, desempeñando mi cargo en la escuela, en 1938, fui movilizado como soldado profesor de la escuela de Caballeros mutilados de guerra por la patria y tenía un puesto como soldado de máxima confianza.

4. Nunca pertenecí a organizaciones políticas ni sindicales de tendencia izquierdista, por ello no entiendo sin ninguna clase de actuación política que se me imponga sanción por ello.

Mejor suerte tuvieron algunos maestros como Teobaldo de Frutos y Frutos, María del Carmen García Salinero, Eulogio González Ajo y Eutiquio Rodríguez García que, a pesar de los cargos iniciales fueron repuestos en sus puestos entre el mes de junio y el de octubre de 1937. En sus expedientes podemos ver cómo a pesar de que los maestros y vecinos Desiderio López y Cipriano Martín informan negativamente sobre ellos ( $y$ en algunos casos el alcalde), no es el caso del sacerdote, que alababa su labor. Teobaldo Frutos y Frutos en cuyo expediente aparece el informe del sacerdote del pueblo de Mozoncillo (Segovia), donde el maestro había ejercido antes de tomar posesión de su cargo en la capital, se lee lo siguiente: «Desempeñaba la enseñanza en sus últimos tiempos en Mozoncillo, conforme al método laico, pero sin perjudicar la religión. En lo demás, se comportó como buen católico».

En el caso de Eulogio González Ajo, María del Carmen García Salinero y Eutiquio Rodríguez ocurre lo mismo. En el informe que emite el párroco de estos tres maestros puede leerse cómo son considerados por los sacerdotes como docentes católicos, apostólicos romanos y fieles cumplidores de su misión educativa cristiana y españolista. Este informe positivo ayuda a que los citados maestros no tengan ningún tipo de sanción y sean repuestos en el cargo, a pesar de no tener todos los pronunciamientos favorables.

Tras el proceso depurador algunos de ellos, como Teobaldo de Frutos y Eulogio González, se mostraron simpatizantes del régimen, realizaron los cursos de orientación y perfeccionamiento del Magisterio, convocados por orden 27 de junio de 1939 y fueron jubilados de sus respectivas escuelas en la década de 1960 como maestros propietarios, a la edad de setenta años.

\subsection{Maestros afines: los docentes de la Nueva España}

En este último apartado tratamos de presentar una reflexión sobre todos aquellos maestros y maestras de la capital de Segovia que fueron confirmados en su cargo sin presentar ningún tipo de sanción. En sus informes se avalaba su buena conducta patriótica y religiosa, así como su intachable conducta moral tanto en la escuela como fuera de ella. Realizaremos un repaso por los expedientes de estos 
maestros, atendiendo a la categoría de género, con el fin de conocer los perfiles de masculinos y femeninos que el franquismo buscaba para los docentes de la nueva España.

Entre los maestros que no recibieron ningún tipo de sanción se encuentran: Ignacio Barba Sanz, Carlos Obejero González, Albino Charle de Pablo, Gabriel Ramos González y Desiderio López Velicia (escuela graduada n.o 1 de los Huertos); y José González Delgado, Cipriano Martín Casado y Francisco Maseda del Peso (Grupo Escolar Colmenares).

Entre todos ellos, Cipriano Martín, Desiderio López, Francisco Maseda, José González e Ignacio Barba habían nacido a finales del siglo XIX y obtuvieron su título de maestros en la primera década del siglo xx. A todos ellos les fueron concedidos varios votos de gracias en las décadas de 1920 y 1930 como reconocimiento a la labor que realizaban al frente de las escuelas e incluso premios en metálico.

En los informes que aparecen en sus expedientes de depuración se destaca de ellos el no haber pertenecido a partidos vinculados con el Frente Popular ni mostrar ideario perturbador ni el aspecto patriótico ni moral ni religioso. Además, se subrayan sus ideas derechistas en la escuela, su buena reputación y el cumplimiento de su deber como maestros sembradores de buenas doctrinas.

Estas ideas resultan especialmente destacables en los expedientes de dos maestros: Desiderio López Velicia y Cipriano Martín Casado. El primero de ellos era presidente de la Asociación de Maestros Españoles. De significación derechista, católica y conservadora, igual que Cipriano Martín (que también pertenecía a dicha asociación) fueron nombrados para informar sobre el resto de sus compañeros tanto en Segovia como en la provincia. La mayoría de sus declaraciones eran muy desfavorables, incluso en contra de lo que decían otras autoridades locales. En algunos casos, incluso, no informaban de la labor pedagógica de sus compañeros, pues la desconocían, pero se atrevían a expresar su labor perniciosa (Vega, 2010, p. 337).

Terminada la depuración, estos dos maestros, junto a los mencionados, volvieron a ocupar sus cargos en los mismos centros. Su recorrido profesional fue reconocido por el Régimen. Por ejemplo, José González Delgado ejerce el cargo de secretario de la Junta Provincial de Huérfanos de Magisterio hasta 1947, acogidos en la residencia San José de la capital y después fue nombrado director interino de la Graduada número 2, "Primo de Rivera» (anteriormente Grupo Escolar Colmenares). Su compañero Cipriano Martín, seguirá después de la depuración ocupando su cargo de maestro propietario hasta el 26 de diciembre de 1957, año de su jubilación. También Desiderio López Velicia se convierte en director de la Graduada n.o 1 hasta 1938, cargo que después deja a su compañero, Gabriel Ramos González. La jubilación de Desiderio en la primavera de 1948 después de cuarenta y cuatro años de servicio fue celebrada en la capital con entusiasmo, contando con la presencia de la presidenta de la Asociación Católica del Magisterio de la provincia y el Inspector Jefe, pidiendo incluso su petición a las autoridades de la Medalla de la ciudad, 
junto a su compañero Ignacio Barba ${ }^{14}$. Francisco Maseda del Peso falleció en 1938 como maestro del grupo escolar Colmenares. De Albino Charle de Pablo y de José Obejero no se disponen de datos. Del primero de ellos, su expediente antiguo ha sido sustraído del Archivo Territorial de Segovia, aunque sabemos por las actas de la Sociedad de Amigos de la Escuela del grupo escolar Colmenares, que fue director del centro en 1946, cargo que dejó al ser nombrado como director en el Grupo Macías Picavea de Valladolid.

Si nos detenemos en el grupo de maestras, vemos cómo un número más numeroso de ellas que de maestros fueron confirmadas en sus cargos, pues presentaban este perfil contrario a las políticas educativas del gobierno republicano que valoraban de forma muy positiva las comisiones depuradoras. Es el caso de Magdalena Sintes Órfila, Consuelo Gil de Bernabé, María Mercedes López de Letona, Zoila Martín González (escuela graduada n.2 de niñas de Santa Eulalia); Agustina Vinuesa Zamariego, María Amparo Ballesteros Guerra, Dolores de la Fuente Moraleda (Escuela Graduada aneja a la Normal); Estefanía Borregón Rincón, Teodora Diez Arévalo (Unitaria de niñas número 1 del barrio de San Lorenzo); y María del Pilar Arenal Baz, Vicenta Sierra Hernández, María Asunción Moreno Páramo (Graduada número 1 de niñas de la Plaza de los Huertos).

Algunas de ellas, como por ejemplo María Asunción Moreno, Teodora Díez o Estefanía Borregón, habían estudiado en el Plan Profesional de 1914 y habían desempeñado positivamente su labor durante el periodo republicano, a pesar de que en sus expedientes se ve firmemente como a lo largo de su carrera profesional van dejando a un lado su labor como maestras y se impone su función como madres y esposas.

En el ideario pedagógico de todas las maestras citadas en este apartado, igual que ocurre con los maestros mencionados con anterioridad, aparecen fuertemente marcados los ideales de Patria y Religión. Para ellas, resultaba importante que se hubieran mantenido al margen de la política durante su trayectoria profesional. Un ejemplo de esta realidad aparece en el expediente de Agustina Vinuesa, en el que el informe del Gobernador Civil reza diciendo:

Después de varias consultas y averiguaciones resulta ser persona de buenas costumbres sin que se conozca manifestación alguna de su actuación política, estando las familias de sus alumnos contentas por la enseñanza que da a sus hijos, sin que hayan observado en la maestra inclinación política alguna.

Además, se valoraba positivamente que la maestra hiciera alarde de su religiosidad no solo dentro sino también fuera del aula y se mostrara sumisa a las prescripciones de la Iglesia y los deberes cristianos. Ejemplo de esta característica lo

${ }^{14}$ Escuela española. 27 de mayo de 1948. Página 330 
vemos en casi todos los expedientes de las maestras mencionadas. Sirva de ejemplo el informe que redacta el párroco para el expediente de la maestra María del Pilar Arenal Baz.

Persona muy digna, católica, sumisa a las prescripciones de la Iglesia, esclava del cumplimiento de su deber profesional y totalmente ajena a toda participación en ese movimiento e implantación de planes laicistas en la enseñanza primaria, desarrollado en el último quinquenio.

Un punto favorable para ellas también es que fueran defensoras del orden de la familia y de los valores del patriarcado. Lo vemos, por ejemplo, en el informe de Vicenta Sierra que redactan los vecinos y maestros Desiderio López y Cipriano Martín:

Excelente cristiana y de hábitos loables, de firmes ideas derechistas, bien relacionada y conceptuada. Defensora del orden de la familia, de la tradición y de la Patria y cumplidora de sus deberes escolares, ha hecho siempre labor provechosa en la escuela.

El perfil sumiso de las maestras y su disciplinado modo de trabajar siendo puntuales con su labor, ajenas a cualquier movilización política que contradijera el orden tradicional y defensoras de las buenas costumbres cristianas transmitidas a la infancia, fueron aspectos esenciales para que estas no solo fueran confirmadas en sus respectivos cargos, sino que en sus informes se reconociera incluso su labor como docentes por parte de todos los hombres que formaban parte de la Comisión depuradora segoviana. Especial mención merece en este punto la maestra salmantina Zoila Martín González, que pasó de ser maestra propietaria antes de la guerra en la Graduada de Santa Eulalia de Segovia, a directora de la misma escuela en 1945, cargo que ostentó varios años y que ocupaba antes de su jubilación en 1962.

\section{DISCUSIÓN Y CONCLUSIONES}

El panorama que se dibuja tras el estudio realizado refleja cómo el magisterio de la capital segoviana no era especialmente activo en el ámbito político ni en el sindical. Más de un $55 \%$ de los maestros y maestras no recibieron ningún tipo de sanción, pues su perfil se adecuaba a las guías normativas del Nuevo Estado.

Respecto a los cargos de los que fueron acusados los maestros de la capital segoviana, se constata, de acuerdo con Ramos (2005), que el mayor número de cargos y tipología corresponden a los expedientes masculinos. Aunque muchas fueron las mujeres que fueron acusadas por simpatizar con la política de izquierdas, solo se 
les pudo calificar como «izquierdistas», debido a que la afiliación de la mujer a los partidos y sindicatos era minoritaria, y, por tanto, se les acusó de esta forma de colaboracionistas o simpatizantes (Martín, Grana y Sanchidrián, 2010, p. 250). La falta de argumentos por parte de la comisión depuradora segoviana para realizar dichas acusaciones permitió que fueran de nuevo repuestas en sus cargos sin tener todos los pronunciamientos favorables

Además, se ha comprobado cómo no solo lo maestros sindicalistas y aquellos que participaban en política eran represaliados, sino que las comisiones perseguían a los maestros con un espíritu renovador, como fue el caso de María Fuencisla Moreno, Pedro Natalías y Ángel Gracia, estos dos últimos asesinados por el simple hecho de emprender una educación progresista y ser activos en la renovación de la escuela de los años treinta.

Hay que reseñar también, que las comisiones depuradoras tuvieron especial interés en castigar a aquellas mujeres que no cumplieran con el modelo femenino tradicional y constituyeran un mal ejemplo por su conducta social. Su conducta transgresora ponía en jaque la estabilidad del patriarcado y por ello no se dudó en separar del cargo a los «malos ejemplos». Cuatro maestras que habían sido reconocidas con votos de gracia por su labor en los años previos a la represión, fueron definitivamente separadas de su profesión por manifestar esta conducta que se olvidaba de la buena labor pedagógica de las docentes para adentrarse en su vida personal.

Respecto a las maestras que fueron aceptadas en sus cargos sin sanciones, hemos comprobado que su número es mayor que el de los maestros. Coincidiendo con Ramos (2004) la vuelta a un modelo social tradicional implicaba para la mujer la pérdida de unos derechos adquiridos durante el periodo republicano que no muchas maestras pusieron en práctica, hecho que les facilitó su adhesión al Nuevo Estado.

Pero, además, en línea con Fernández y Agulló (1999b) el trabajo evidencia que las maestras sufrieron menor represión que los maestros. Las razones que se desprenden de esta menor represión son: a) la ideología de los vencedores reforzaba el papel secundario de la mujer y por ello trataba de protegerla, como hemos visto en el expediente depurador de la maestra María Fuencisla Moreno; b) las maestras no habían tenido un protagonismo destacado en la renovación pedagógica y por ello eran menos sancionadas que sus compañeros, hecho que se ha podido constatar a lo largo de todo el análisis; c) las maestras no eran protagonistas en la vida política y sindical de los años treinta, por ello sufren en menor medida sus efectos.

Quizá el importante número de maestros y maestras que fueron en la capital de Segovia confirmados en sus cargos debería hacernos cuestionar, como explican autores como Morente (2001) y Vega (2010), el tópico del Magisterio como baluarte del programa republicano y empezar a considerar a este cuerpo 
profesional como un ente complejo donde convivían diversas ideologías e intereses. Por un lado, estaban aquellos maestros comprometidos con la renovación pedagógica y por otro, quienes no solo no tenían inquietudes por ella, sino que eran contrarios a la tradición.

Dentro de este segundo grupo de maestros, hemos comprobado que existían dos modelos en función del género. En el caso masculino, se presenta un hombre defensor de los valores patrióticos y del orden social tradicional, solía participar activamente en la vida religiosa de la capital y su labor había sido reconocida en la dictadura de Primo de Rivera. En el caso femenino, nos encontramos con un modelo de maestra sumisa, familiar, religiosa y costumbrista.

Es importante destacar cómo después del proceso depurador muchos son los maestros masculinos que ocupan puestos de referencia a nivel social y educativo en la configuración del Nuevo Estado. Mientras, muchas de las maestras que fueron confirmadas en sus cargos abandonan la función docente o la solapan a su labor como madres y esposas. En los expedientes se ha comprobado cómo algunas de estas maestras piden excedencias continuamente para el cuidado de los hijos o familiares a su cargo. Otras desempeñan su labor como maestras siempre defendiendo los valores nacionalcatólicos. Aunque algunas de ellas tienen expedientes brillantes y fueron reconocidas en el periodo previo a la guerra por su buena labor en las aulas, durante la dictadura no aparecen sus nombres reseñados en la prensa local ni en documentos oficiales, aspecto diferente en el caso de los hombres.

Podemos concluir, por tanto, diciendo que la depuración del magisterio en la capital segoviana afectó en mayor medida a los maestros, pero algunas maestras también sufrieron el castigo por su transgresión a los modelos tradicionales. Incluso, como se ha visto en el caso de María Fuencisla Moreno y Carlota Benito, sus castigos no solo fueron las sanciones recibidas, sino el rechazo social al que se vieron sometidas por sus «deslices» políticos, sindicales y morales inexcusables.

No queremos terminar esta investigación sin destacar algunas de las limitaciones que se presentan en el estudio. La más importante nace de la naturaleza de la fuente principal, los expedientes de depuración, que como hemos podido comprobar, no reflejan en muchos de los casos toda la documentación sobre los docentes ni sus acusaciones. Esta información ha tratado de ser completada utilizando fuentes de otros archivos, a pesar de que no se ha conseguido en todos los casos. Otra limitación que destacar es que sería oportuno poner en discusión los resultados extraídos en este trabajo, con los de una investigación más general que abordara la depuración en la provincia, tomando las variables cualitativas y de género como guías del estudio, con el objetivo de comparar los resultados. Precisamente estas limitaciones son las que nos llevan a plantear trabajos futuros, como realizar una investigación de la depuración del magisterio femenino en la provincia, o profundizar en las biografías de cada uno de los maestros y maestras que se presentan en esta investigación. 


\section{REFERENCIAS BIBLIOGRÁFICAS}

Abós, P. (Coord.) (2015). Franquismo y magisterio. Represión y depuración de maestros en la provincia de Teruel. Zaragoza: Prensas Universitarias.

Benito Santos, M. (2008). La depuración del magisterio en la provincia de Ciudad Real tras la Guerra Civil: Los expedientes de depuración. En F. Alía Miranda, A. R. del Valle Calzado y O. M. Morales Encinas (Eds.), La guerra civil en Castilla-La Mancha, 70 años después: Actas del Congreso Internacional (pp. 1661-1676). Cuenca: Ediciones de la Universidad de Castilla-La Mancha.

Berzal de la Rosa, E. Rodríguez González, J. (Coords.). (2010). Muerte y represión en el Magisterio de Castilla y León. León: Fundación 27 de marzo.

Caro Cancela, D. (2015). La cultura de los espacios socialistas. Casas del Pueblo y Centros Obreros en la Segunda República Española. Cahiers de civilisation espagnole contemporaine, 2, pp. 1-10. https://doi.org/10.4000/ccec.5595.

Carr, Raymond. (1985). Estudios sobre la República y la guerra civil. Madrid: Sarpe.

Chaves Palacios, J. (1995). La represión en la provincia de Cáceres durante la Guerra Civil (1936-1939). Cáceres: Universidad de Extremadura.

Cid Fernández, X. M. (2017). A represión franquista en Ourense: novos argumentos contra a desmemoria da persecución sufrida polo maxisterio. Sarmiento: Revista Galego-Portuguesa de Historia da Educación, 21, pp. 73-99. https:// doi.org/10.17979/srgphe.2017.21.0.4821.

Circular de 7 de diciembre de 1936. Boletín de la Junta Técnica del Estado, 10 de diciembre de 1936.

Costa Rico, A. (1997). A chegada da dictadura. Purga e represión de ensinantes (1936-1940). Revista Galega de Educación, 28, pp. 88-91.

Costa Rico, A. y Bolaño Amigo, U. (2017). Represión política e castigo do profesorado republicano na provincia de Lugo: As consecuencias do 36. Sarmiento: Revista Galego-Portuguesa de Historia da Educación, 21, pp. 101-118. https://doi. org/10.17979/srgphe.2017.21.0.4590. 
Domenech Jiménez, M. I. (2016). Las maestras de la guerra civil y el primer franquismo en la provincia de Alicante (Tesis doctoral). Alicante, Universidad de Alicante.

Dueñas Díez, C. (2014). Educadores del pueblo. La educación en Segovia 1900-1936. En J. L. García Hourcade y J. M. Santamaría López (Coords.), Segovia en el siglo XX (pp. 45-64). Segovia: Real Academia de Historia y Arte de San Quirce.

Dueñas Díez, C. de. y Grimau Martínez, L. (2004). La represión franquista de la enseñanza en Segovia. Valladolid: Ámbito.

Fernández Soria, J. M. y Agulló Díaz, C. (1999a). Maestros valencianos bajo el franquismo: la depuración del magisterio, 1939-1944. Valencia: Institució Alfons el Magnánim.

Fernández Soria, J. M. y Agulló Díaz, C. (1999b). Depuración de maestras en el franquismo. Studia historica. Historia contemporánea, 17, pp. 249-270.

Gabriel, N. de. (2017). O proceso de depuración do maxisterio na provincia da Coruña. Sarmiento: Revista Galego-Portuguesa de Historia da Educación, 21, pp. 119-158. https://doi.org/10.17979/srgphe.2017.21.0.4826.

Gallego Lorenzo, J. (2017). La depuración de los maestros en la guerra civil española y en el franquismo en Albacete (1936-1942). Universidad de Castilla-La Mancha.

García Díaz, J. M. (2017). La depuración del magisterio nacional en A Coruña (Tesis doctoral). Vigo, Universidade de Vigo.

García Madrid, A. (2005). La depuración del Magisterio nacional en la provincia de Salamanca. Avance de estudio. Papeles salmantinos de educación, 4, pp. 137192. https://doi.org/10.36576/summa.29807.

González-Agàpito, J. y Marqués i Sureda, S. (1996). La repressió del profesorat a Catalunya sota el Franquismo (1939-1943). Segons les dades del Ministeri d 'Educació Nacional. Barcelona: Institut d'Estudis Catalans.

Gudín de la Lama, E., Gutiérrez Flores, J., Obregón Goyarrola, F. y Menéndez Criado, E. (2012). La depuración republicana del magisterio cántabro durante la Guerra Civil. Historia Actual Online, 29, pp. 163-176. 
Gutiérrez Flores, J. (2010). La represión del magisterio en Palencia. En E. Berzal de la Rosa y J. Rodríguez González (Coords.). (2010). Muerte y represión en el Magisterio de Castilla y León (pp. 201-276). León: Fundación 27 de marzo.

Hernández Díaz, J. M. (2012). Muerte y represión en el Magisterio de Castilla y León (recensión). Aula, 18, pp. 249-250.

Hernández Hernández, J. M. (1989). La represión franquista sobre los maestros en la provincia de Santa Cruz de Tenerife. Revista Periferia, 4, pp. 93-105.

Hernández Huerta, J. L. (2004). Bosquejo de la actualidad de la educación española. Foro de Educación, 4, pp. 5-18.

Hernández Huerta, J. L. y Sánchez Blanco, L. (2008). La represión franquista de la enseñanza. Fuentes y bibliografía (1975-2007) para el estudio de la depuración del magisterio nacional. Papeles salmantinos de educación, 11, pp. 231-266. https://doi.org/10.36576/summa.29454.

Jiménez Madrid, R. (1997). La depuración de maestros en Murcia. 1939-1942 (primeros papeles). Murcia: Universidad de Murcia.

Martín Zuñiga, F. y Grana Gil, I. (2019). Una visión global de la depuración franquista del profesorado: semejanzas y peculiaridades. Revista de Estudios Regionales, 114, pp. 71-89.

Martín Zúñiga, F., Grana Gil, I. y Sanchidrián Blanco, C. (2010). La depuración franquista de los docentes: control y sometimiento ideológico del profesorado de instituto. Historia de la Educación: Revista interuniversitaria, 29, pp. 241258.

Martínez Aznal, R. (2015). La represión al Magisterio y a las mujeres en la Ribera estellesa de Navarra (1936-1939). Huarte de San Juan. Geografía e historia, 22, pp. 219-240.

Martínez Martínez, M. A. (2015). La depuración franquista del magisterio en las escuelas primarias de Carabanchel. Cabás, 14, pp. 16-37.

Martínez Pereda, L. (2006). La depuración franquista en el magisterio zamorano: un estudio cuantitativo. Anuario del Instituto de Estudios Zamoranos Florián de Ocampo, 23, pp. 251-292. 
Martínez Pereda, L. (2008). La depuración franquista en el magisterio nacional en el norte de Zamora (1936-1943). Benavente: Centro de Estudios Benaventanos "Ledo del Pozo».

Mayo Lorenzo, B. (2012). La depuración del magisterio en la provincia de León (Tesis doctoral). Salamanca, Universidad Pontificia de Salamanca.

Miró, S. (1998). Maestros depurados en Baleares durante la guerra civil. Palma de Mallorca: Lleonard Muntaner.

Moreno Yuste, J.M. (2019). Segovia 1900-1936. Diccionario Biográfico. Segovia: Real Academia de Historia y Arte de San Quirce.

Morente Valero, F. (1994). La depuración del magisterio en la provincia de Barcelona al término de la guerra civil. Madrid, Ministerio de Educación y Ciencia.

Morente Valero, F. (1996). Tradición y represión: la depuración del magisterio de Barcelona, (1939-1942). Barcelona: Promociones y Publicaciones Universitarias, PPU.

Morente Valero, F. (2001). La depuración franquista del magisterio público. Un estado de la cuestión. Hispania, 61(208), pp. 661-688. https://doi.org/10.3989/ hispania.2001.v61.i208.301.

Negrín Fajardo, O. (2010). Memoria histórica y educación en Canarias: depuración y represión del magisterio en la provincia de Las Palmas (1936-1942). Las Palmas de Gran Canaria: Casa de Colón.

Onandia Ruiz, B. (2019). Entre el pecado y la lujuria: la inmoralidad pública durante el franquismo. Raudem, Revista de estudios de las mujeres, 6, pp. 172- 197. https://doi.org/10.25115/raudem.v6i0.2398.

Ortiz Heras, M. (1991). La depuración del Magisterio en la provincia de Albacete. El lenguaje de los expedientes de depuración. En J. J. Carreras Ares y M. A. Ruiz Carnicer (Coords.), La universidad española bajo el régimen de Franco: Actas del congreso celebrado en Zaragoza entre el 8 y el 11 de noviembre de 1989 (pp. 237-256). Zaragoza: Institución Fernando el católico.

Pablo Lobo, C. de. (2004). La depuración del magisterio primario en la provincia de Soria. Revista de Soria, 47, pp. 113-122. 
Paniagua, J. (2003). Diccionario biográfico de políticos valencianos: 1810-2005. Valencia: Institució Alfons el Magnànim.

Pérez Vera, E. (2018). Sobre la depuración de docentes bajo el franquismo. En A. Egido León y J. J. Montes Salguero (Eds.), Mujer, franquismo y represión: una deuda histórica (pp. 323-348). Madrid: Sanz y Torres.

Piamonte, V. A. (2014). El significado de la revolución asturiana de 1934 en el proceso de desestarización del comunismo argentino: los orígenes del «frente popular» en la Argentina. Revista Estudios, 29, pp. 1-29.

Plaza Benimelo, N. (2015). La depuración del magisterio como forma de control social (Tesis doctoral). Barcelona, Universitat de Barcelona.

Pont Sastre, A. (2001). Los maestros en Guadalajara: proceso depurador y entorno social (1936-1939). Espacio, Tiempo y Forma. Serie V, Historia Contemporánea, 14, pp. 287-308. https://doi.org/10.5944/etfv.14.2001.3056.

Pont Sastre, A. (2006). El magisterio en la provincia de Guadalajara (1931-1940): Depuración y represión. Alcalá de Henares: Servicio de publicaciones de la Universidad de Alcalá.

Porto Ucha, A. S. y Vázquez Ramil, R. (2017). A depuración do maxisterio primario na provincia de Pontevedra (1936-1942). Sarmiento: Revista GalegoPortuguesa de Historia da Educación, 21, pp. 31-72. https://doi.org/10.17979/ srgphe.2017.21.0.4587.

Pozo Fernández, M. C. (2001). La depuración del magisterio nacional en la ciudad de Málaga. Málaga: Diputación Provincial de Málaga.

Pozo Fernández, M. C. (2010). La depuración del magisterio nacional en la provincia de Málaga (1937-1942) (Tesis doctoral). Málaga, Universidad de Málaga.

Pozo Fernández, M. C. y Ventajas Dote, F. (2003). La represión franquista del Magisterio malagueño a través de los expedientes de depuración. En L. M. Naya Garmendia y P. Dávila Balsera (Eds.), La infancia en la historia: Espacios y representaciones. Volumen 2 (pp. 748-762). Donostia-San Sebastián: Erein.

Ramos Zamora, S. (2004). La depuración del magisterio de primera enseñanza en Castilla-La Mancha (1936-1945). (Tesis Doctoral). Madrid: Universidad Complutense de Madrid. 
Ramos Zamora, S. (2005). Maestras represaliadas por el gobierno franquista. Arenal, 12(1), pp. 113-145.

Ramos Zamora, S. (2006). Control y represión: estudio comparado de los resultados de la depuración del magisterio primario en España. Revista Complutense de Educación, 17(1), pp. 169-184.

Rodríguez Arroyo, J. C. (2012). La depuración del Magisterio Primario de Sierra de Gata durante la Guerra Civil. Revista de estudios extremeños, 68(3), pp. 14691488.

Rojas Castellano, F. (2011). La depuración del magisterio público en Coria del Rio (1936). Anuario de estudios locales, 5, pp. 43-54.

Ruiz Berrio, J. (1976). El método histórico en la investigación histórica de la Educación. Revista Española de Pedagogía, 134, pp. 449-475.

Ruiz González, C. (2017). Mitos y memoria de la represión franquista de los docentes en la provincia de Zamora. Studia Zamorensia, 16, pp. 39-59.

Sáez y Romero, M. (1940). Periodismo segoviano. Madrid: Instituto Diego de Colmenares - Consejo Superior de Investigaciones Científicas.

San Millán y Gallarín, C. (2016). La depuración del Magisterio nacional en la localidad malagueña de Alhaurín de la Torre. Jábega, 108, pp. 84-100.

Sonlleva Velasco, M. y Sanz Simón, C. (2017). El grupo escolar Primo de Rivera. Dibujando el perfil de la educación franquista en la ciudad de Segovia. Cabás, 18, pp. 152-159.

Tristán García, F. (2017). La depuración del Magisterio de las comarcas de Baza y Huéscar (1936-1963). Péndulo. Papeles de Bastitania, 18, pp. 9-60.

Uria, J. (1984). La depuración de maestros asturianos en los años 40. Andecha Pedagógica, 12, pp. 9-11.

Vega Sombría, S. (2002). Control sociopolítico e imposición ideológica: la provincia de Segovia 1936-1939. Un episodio de la implantación del régimen de Franco (Tesis doctoral). Madrid, Universidad Complutense de Madrid. 
Vega Sombría, S. (2004). La represión en la provincia de Segovia en los orígenes del régimen de Franco. Hispania Nova, 4, pp. 1-22.

Vega Sombría, S. (2010). La depuración del personal docente en la provincia de Segovia. En E. Berzal de la Rosa y J. Rodríguez González (Coords.) (2010). Muerte y represión en el Magisterio de Castilla y León (pp. 323-368). León: Fundación 27 de marzo.

Vilanova Candau, V. (2015). La educación durante la Segunda República, la Guerra Civil y el primer Franquismo en las comarcas de Castellón. La depuración del Magisterio (Tesis doctoral). Castellón, Universitat Jaume I.

Vilanova Candau, V. y Monlleó Peris, R. (2019). Miedo contenido y silencio sumiso. La depuración del magisterio en Castellón (1939-1943). Castellón, Universitat Jaume I. https://doi.org/10.6035/HistoriaMemoria.2019.9. 
Página intencionadamente en blanco. 